\title{
AL-amyloidosis and light-chain deposition disease light chains induce divergent phenotypic transformations of human mesangial cells
}

\author{
John Keeling ${ }^{1,2,3}$, Jiamin Teng ${ }^{1}$ and Guillermo A Herrera ${ }^{1,2,3,4}$ \\ ${ }^{1}$ Department of Pathology; ${ }^{2}$ Department of Cellular Biology; ${ }^{3}$ Department of Anatomy and ${ }^{4}$ Department of \\ Medicine, Louisiana State University Health Sciences, Shreveport, LA, USA
}

\begin{abstract}
Human mesangial cells (HMCs) are injured by either excessive amounts or abnormal light chains (LCs), or a combination of both in patients with plasma cell dyscrasias. Consequently, these HMCs undergo phenotypic transformations. HMCs were incubated with eight different light-chains (LCs) for $96 \mathrm{~h}$. These cells, in addition to 51 patient samples from patients with AL-amyloidosis (AL-Am), light-chain deposition disease (LCDD), myeloma cast nephropathy (MCN) and controls were analyzed by immunohistochemistry for CD68, musclespecific actin (MSA), smooth muscle actin (SMA), CD14, and Ham56 protein expressions. All samples were also studied using electron microscopy. Greater staining (four- and three-fold) expressions of CD68 and Ham56, respectively, were observed in the HMCs incubated with AL-Am-LCs compared to those with LCDD-LCs and control. SMA expression levels were five-fold higher in LCDD-LC-treated cells compared to the other categories of LC-treated and control cells. Similar results were obtained in the renal specimens, however, CD68 levels were 12-fold higher in the AL-Am cases compared to the LCDD cases, respectively. Conversely, MSA and SMA levels were three fold higher in the LCDD cases than in the AL-Am ones. No CD14 expression was noted in any of the samples and CD-34 staining of HMCs treated with the various LCs only showed rare positive cells. Dynamic real-time studies to visualize the rough endoplasmic reticulum (RER) and lysosomal compartments in HMCs incubated with LCDD and AL-Am-LCs showed striking expansion of each of the above-mentioned compartments, respectively. This indicates the presence of more RER in the LCDD-LC-treated HMCs and a striking increase in lysosomes noticeable in the AL-Am-LC-treated cells. Data obtained in this study highlighted that HMCs incubated with LCDD-LCs undergo a myofibroblastic phenotypic transformation, while AL-Am-LCs induce a macrophage-like phenotype in these cells.

Laboratory Investigation (2004) 84, 1322-1338, advance online publication, 2 August 2004; doi:10.1038/labinvest.3700161
\end{abstract}

Keywords: myeloma; light chains; CD68; MSA; SMA; mesangium; ultrastructure; immunohistochemistry

The renal glomerulus is a complex structure, consisting of a number of cell types performing specialized functions, which all culminate in the filtration of plasma and the production of urine. The glomerular mesangial cell is one of the major cell types and accounts for $30-40 \%$ of the total population of the glomerulus. ${ }^{1}$ These cells, being of mesenchyme origin, are derived from smooth muscle cell precursors and, although being able at times to perform phagocytic functions, are not from the

Correspondence: Dr GA Herrera, MD, Department of Pathology, Louisiana State University Health Sciences, 1501 Kings Highway, Shreveport, LA 71130, USA.

E-mail: gherre@lsuhsc.edu

Received 12 December 2003; revised 16 June 2004; accepted 22 June 2004; published online 2 August 2004 mononuclear phagocytic (monocytic) system. Ultrastructural and morphological evidence show the glomerular mesangial cells to be similar to smooth muscle cells and express many of their associated proteins.

Ultrastructurally, the mesangial cell appears to be remarkably irregular in shape with numerous processes of varying lengths projecting into the surrounding extracellular matrix (ECM) and connecting with the glomerular basement membrane (GBM). The cell generally has an indented nucleus and a small amount of cytoplasmic organelles such as mitochondria, lysosomes, ribosomes, endoplasmic reticulum and stacked Golgi cysternae. ${ }^{2}$ Numerous bundles of small intracellular filaments with spindle densities or dense bodies and associated attachment plaques are present in the normal mesangial 


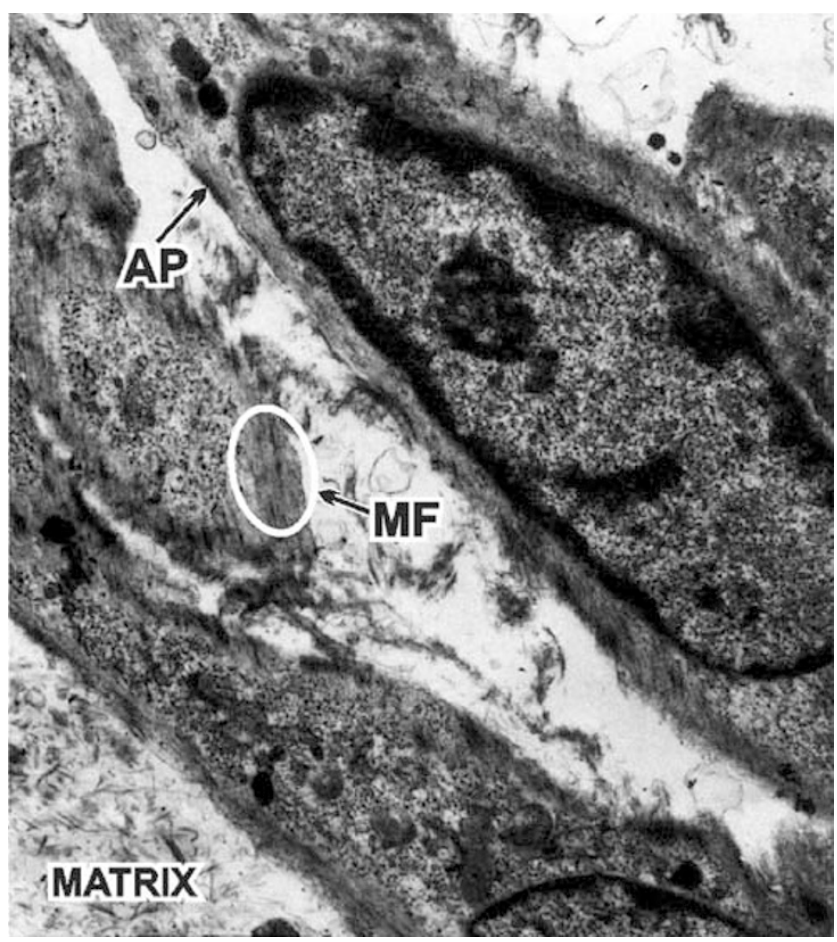

Figure 1 Ultrastructural appearance of normal HMCs cultured on a Matrigel base (matrix). Note the presence of attachment plaques (AP) and myofilaments (MF). TEM (uranyl acetate \& lead citrate) $\times 18500$.

cells indicative of smooth muscle differentiation (Figure 1).

The functions of the glomerular mesangial cell are many and varied. ${ }^{2-4}$ These include primary support for the glomerular capillary loops, extracellular matrix production and remodeling through its production and modulation of matrix metalloproteinases (MMPs). The production of chemokines, adhesion molecules, and growth factors, and the processing of macromolecules such as lipids, immune complexes and advanced glycation endproducts (AGE) are also important functions of the mesangial cells. ${ }^{5}$

Mesangial cells are able to contract in response to a variety of agonists. This causes retraction of the glomerular capillaries, resulting in decreased capillary surface area and filtration rates. In addition, mesangial cells may also be involved in the response to mechanical injury, cell proliferation and basement membrane remodeling. Evidence has shown that glomerular injury may induce phenotypic changes in mesangial cells characterized by an increased expression of smooth muscle-like proteins such as $\alpha$-smooth muscle actin (SMA) and the secretion of interstitial collagens which are absent from the normal mesangial matrix. ${ }^{1,6,7}$ This was also evident in rat mesangial cells where SMA was not detected in the normal glomerulus while present in cultured cells and is attributed to an apparent de novo expression of the protein in response to altered glomerular hemodynamics wherein the mesangial cell is exposed to increased stretch. ${ }^{8,9}$ Also, other proteins such as desmin may be demonstrated in the normal mesangial cell both in vitro and in vivo and has served in their characterization. ${ }^{10-12}$

Actin, one of the most highly conserved proteins in humans, has been determined to exist in six isoforms; four of which have been used as differentiation markers of muscle tissue, while two are ubiquitous. The isoforms show remarkable sequence homology $(>90 \%)$ with much of this homology expressed in their 18 amino-terminal residues (50$60 \%) .^{13}$ While little is known of the functions attributed to the actin isoforms, it has been shown that differences in their distribution are evident in smooth muscle cells from various organs. SMA has been reported ${ }^{14}$ to be highly expressed in HMCs in response to injury and proliferative glomerulopathies.

Within the glomeruli, abnormal LCs produced by neoplastic plasma cells contribute to two distinct patterns of injury. Fibrillary monoclonal LC-related renal disease seen in AL-amyloidosis (AL-Am), and light-chain deposition disease (LCDD) characterized by the granular LC deposition constitute these patterns. $\lambda$ LCs are 2-3 times more commonly associated with AL-amyloidosis than $\kappa$ LCs. $^{15}$ Solomon et $a l^{16}$ have reported that $\lambda$ VI LCs are more specifically associated with amyloidosis. Corroborating evidence has been provided by Comenzo et $a l^{17}$ demonstrating a striking tropism of the $\lambda \mathrm{VI}$ LCs for glomerular amyloidosis. In contrast, LCDD is usually associated with $\kappa$ LCs predominantly $\kappa$ I and IV.

In amyloidosis, amyloid deposition is first seen in the mesangium with the normal mesangial matrix being replaced by amyloid. ${ }^{18-20}$ Progression of the disease results in further amyloid deposition within the glomerulus and may involve the interstitium and vasculature. Ultrastructural examination of amyloid reveals randomly distributed, nonbranching fibrils which are $7-10 \mathrm{~nm}$ in diameter, while polarized light microscopy of these deposits reveal an apple-green birefringence when stained with Congo Red dye. The accumulation of these fibrils in the kidney and other organs of the body might be attributed to the failure of the immune system in recognizing amyloid as foreign in nature. ${ }^{21}$

A pattern of nodular glomerulosclerosis is commonly seen in LCDD. ${ }^{20}$ Ultrastructurally, LC deposits may be seen as punctate, granular, electron-dense materials in the glomeruli, the interstitium, along the tubular basement membranes, or in blood vessel walls. In the glomeruli, this striking mesangial nodularity results from the deposition of extracellular matrix proteins mixed with monotypic LC deposits.

The HMCs affected by LCs in AL-amyloidosis, show suppression of SMA due to the loss of myofilaments and overexpression of CD68. The presence of the latter, results from the acquisition of lysosomes, resulting in a macrophage-like 
phenotypic transformation. ${ }^{22,23}$ The endocytosis and catabolism of amyloidogenic LCs in the acquired lysosomes has been proposed by Shirahama and Cohen $^{24,25}$ to be a key step in the formation of amyloid.

In contrast, the mesangial cells in LCDD acquire a prominent rough endoplasmic reticulum, overexpress $\alpha$-smooth muscle actin and produce a variety of extracellular matrix proteins including fibrillary collagens (such as type I and III), suggesting a myofibroblastic phenotype. Myofibroblasts described in other tissues have been shown to be involved in matrix deposition and wound healing. ${ }^{26,27}$ Mesangial cells are crucial in the generation of glomerulosclerosis. ${ }^{28,29}$

\section{Materials and methods}

\section{Isolation of HMCs}

HMCs were procured from unused kidney tissue that was obtained from normal areas of nephrectomy specimens removed for neoplastic conditions away from the tumoral lesions. The cortices from these kidneys were minced and pressed through sterile stainless-steel sieves of various pore diameters (315, 250 and $180 \mu \mathrm{m}$ ) as described. ${ }^{30}$ Whole glomeruli retained on the $180 \mu \mathrm{m}$ sieve were collected and then washed in sterile Hank's-buffered saline solution and centrifuged. The glomerular pellets were resuspended in HEPES-buffered HBSS (pH 7.4) containing $750 \mu \mathrm{g} / \mathrm{ml}$ collagenase IV (Sigma Chemical Company, St Louis, MO, USA). After $30 \mathrm{~min}$ incubation with gentle agitation, the suspension was centrifuged at $1000 \mathrm{rpm}$ for $10 \mathrm{~min}$. The pellets were washed twice and resuspended in complete medium containing RPMI 1640 (Life TechnologiesGibco, Grand Island, NY, USA), buffered with $12.5 \mathrm{mM}$ HEPES (Sigma Chemical Company), supplemented with heat-inactivated $15 \%$ fetal calf serum (Life Technologies), penicillin $100 \mathrm{U} / \mathrm{ml}$, streptomycin $100 \mu \mathrm{g} / \mathrm{ml}, 5 \mu \mathrm{g} / \mathrm{ml}$ bovine insulin, $2 \mathrm{mM}$ L-glutamine, $5 \mu \mathrm{g} / \mathrm{ml}$ transferrin, $5 \mu \mathrm{g} / \mathrm{ml}$ sodium selenite, and $1 \mathrm{mM}$ sodium pyruvate (all from Sigma), and plated onto $100 \mu \mathrm{m}^{2}$ tissue culture dishes.

The glomerular cells were carefully assessed for 3-5 days. Once outgrowths were established, the cells were trypsinized, passed through a $75 \mu \mathrm{m}$ sieve to remove the whole glomeruli, and replated on tissue culture dishes. The cells were maintained at $37^{\circ} \mathrm{C}$ in a humidified incubator containing $5 \% \mathrm{CO}_{2}$. Mesangial cells overgrew epithelial cells and became confluent 3-4 weeks after plating. Cells were then trypsinized and transferred to eight-well chambered slides. Ultrastructural examination and immunohistochemical staining positive for musclespecific actin and vimentin, negative for keratin and factor VIII, confirmed the presence of a homogeneous population of mesangial cells. These mesan- gial cells were then frozen at $-70^{\circ} \mathrm{C}$ and passaged for future experiments.

\section{Isolation and Purification of LCs}

Free LCs were purified from the urine of patients with renal biopsy proven AL-Am (3 LCs) and LCDD (2 LCs) (glomerulopathic LCs) or myeloma cast nephropathy (MCN-LC) (3 LCs) by a series of chromatography steps. Urine is passed over an affinity column comprised of either goat anti-human $\kappa$ or $\lambda$ LC antibody conjugated to Sepharose CL-4B. Free and bound LCs were eluted from the column with $0.1 \mathrm{M}$ glycine, $\mathrm{pH} 2.2$. The purity of the LCs was assessed on immunodiffusion plates and contaminating proteins (IgG, IgA, and albumin) were removed by subsequent repeated passages over affinity columns to which either anti-human IgG, IgA or albumin antibodies were conjugated. The LCs used for the various experiments were not pooled or combined in any fashion. The three AL-Am-LCs were $\lambda$, the two LCDD-LCs were $\kappa$, two of the MCNLCs were $\lambda$ and one $\kappa$.

Purified LCs migrated as a single band when resolved by zone electrophoresis on agarose gels using a $50 \mathrm{mM}$ barbital buffer, $\mathrm{pH}$ 8.6, and consisted entirely of either free $\kappa$ or $\lambda$ protein as determined by immunofixation. The purified LC was then concentrated, dialyzed against $0.9 \% \mathrm{NaCl}$, filtered through a sterile $0.2 \mu \mathrm{m}$ membrane, and stored aseptically in sealed vials at $4^{\circ} \mathrm{C}$.

\section{In Vitro Studies}

HMCs of third passage (P3 HMCs) were thawed from stocks of previously described harvested cells. These cells were seeded onto eight wells tissue culture glass slides and treated with RPMI 1640 (Life Technologies-Gibco, Grand Island, NY, USA), culture medium buffered with $12.5 \mathrm{mM}$ HEPES (Sigma Chemical Company), supplemented with heat inactivated $15 \%$ fetal bovine serum (Life Technologies), penicillin $100 \mathrm{U} / \mathrm{ml}$, streptomycin $100 \mu \mathrm{g} / \mathrm{ml}$ $5 \mu \mathrm{g} / \mathrm{ml}$ bovine insulin, $2 \mathrm{mM}$ glutamine, $5 \mu \mathrm{g} / \mathrm{ml}$ transferrin, $5 \mu \mathrm{g} / \mathrm{ml}$ selenite, and $1 \mathrm{mM}$ sodium pyruvate (all from Sigma). They were allowed to grow to approximately $90 \%$ confluency with media change every 3 days after which they were made quiescent by the use of RPMI 1640 culture medium containing $0.5 \%$ fetal bovine serum (FBS) for $48 \mathrm{~h}$. The cells were then treated in duplicate with either an MCN-LC, an LCDD-LC or an AL-Am-LC diluted in phenol red-free RPMI 1640 containing 0.5\% FBS at a concentration of $10 \mu \mathrm{g} / \mathrm{ml}$. Cells treated with culture medium only served as control. All cells were incubated at $37^{\circ} \mathrm{C}$ and $5 \% \mathrm{CO}_{2}$ for $96 \mathrm{~h}$, after which they were rinsed twice with phosphatebuffered saline (PBS) and fixed for $45 \mathrm{~min}$ in $95 \%$ ethanol. They were then stored at $-70^{\circ} \mathrm{C}$ awaiting immunohistochemical analysis. 
Immunohistochemistry on Paraffin-Embedded Tissue and HMCs from the In Vitro Experiments

In all, 51 formalin-fixed, paraffin-embedded kidney tissues from autopsy and renal biopsies were sectioned at $5 \mu \mathrm{m}$ thick. Totally, 30 negative control samples included 11 cases of ATN, 10 cases of PPE, and nine cases of MCN. Overall, 10 cases of LCDD and 11 cases of AL-Am were also investigated. The sections were deparaffinized by placing them in two changes of xylene for $5 \mathrm{~min}$ each, then $100 \%$ ethanol, $95 \%$ ethanol, and $80 \%$ ethanol for $2 \mathrm{~min}$ each and finally in distilled water. Antigen retrieval using moist heat was performed on these sections by placing them in preheated $0.01 \mathrm{M}$ sodium citrate (pH 6.0) solution and subjecting them to further heating at $100^{\circ} \mathrm{C}$ for $25 \mathrm{~min} .{ }^{31}$

Endogenous peroxidase activity in the tissue sections and the treated HMCs from the in vitro experiments was blocked with $\mathrm{DAKO}^{\mathbb{R}}$ Peroxidase Blocking Reagent (Dako Cytomation) containing $\mathrm{H}_{2} \mathrm{O}_{2}$ for 5 min. Slides were then rinsed three times with PBS (pH 7.4) and blocked with DAKO ${ }^{\circledR}$ Protein Block Serum-Free (Dako Cytomation) containing $0.25 \%$ casein in PBS containing carrier Protein and $\mathrm{NaN}_{3}$ for $5 \mathrm{~min}$ at room temperature. Slides were rinsed three times in tris-buffered saline containing $0.05 \%$ polyoxyethylene-sorbitan monolaurate (Tween-20) (TTBS) prior to the addition of the primary monoclonal antibodies. A volume of $150 \mu \mathrm{l}$ of diluted (Dako antibody diluent) primary antibodies (Dako Cytomation) were added to each slide at the following dilutions ( $\alpha$-SMA (HHF-35 antigen)-1:40 dilution, MSA-1:50 dilution, CD68 (KP1 antigen)-1:100 dilution, CD14 (TUK4 antigen)1/15 dilution, CD34 (QE End 10 antigen)-1/30 and Ham56-pre-diluted). Antibodies to $\kappa$ and $\lambda$ were polyclonal and used at concentrations of 1/800 and $1 / 1000$, respectively. All antibodies were obtained from Dako Corporation, Carpinteria, California. The slides were incubated at $4^{\circ} \mathrm{C}$ overnight and then rinsed three times with TTBS. Each slide was treated with $150 \mu \mathrm{l}$ peroxidase-labeled polymer (Dako Envision System) and incubated for $30 \mathrm{~min}$ at room temperature. Sections were then carefully rinsed three times with TTBS and drained. Each section/slide was treated with chromagen substrate containing diaminobenzidine (DAB) and incubated at room temperature for $7 \mathrm{~min}$. Slides were then quickly rinsed three times in distilled water, counterstained with Harris' hematoxylin for $10 \mathrm{~s}$ at room temperature, and placed in running tap water for $30 \mathrm{~min}$. Sections were dehydrated through ascending concentrations of ethanol, cleared in xylene then mounted with permount.

\section{Grading of Immunohistochemical Staining}

Immunohistochemical staining was assessed based on the presence or absence of brown coloration in the cells, denoted as positive or negative, respec- tively. Staining was graded on a numerical scale of $0-3$, where 0 represented no staining (negative), and 1-3 represented positive staining (three being the most intense staining). Brown staining intensity was assessed by comparison with the staining intensity of the nuclei present in the samples. The final grading would, however, reflect the strongest staining intensity present in the specimens. This criterion mostly, was applied to the grading of the cultured mesangial cells except that the amount of positive cells which were present in a random population of 50 cells were counted. Each positive cell was graded (1-3) then the amount of positive cells was multiplied by their grade to give a maximum score of 150 . Each immunostained specimen was counted three times by two separate examiners.

\section{Controls}

Controls used in the in vitro experiments consisted of HMCs incubated with phenol red-free RPMI 1640 containing $0.5 \%$. FBS and no free LCs. Negative controls for the tissue samples consisted of renal tissue taken from uninvolved portions of nephrectomies performed for renal cell carcinomas, samples from donor kidneys with postperfusion effect (PPE) exhibiting proximal tubular injury, with no glomerular alterations, as a result of renal perfusion aimed at organ preservation prior to transplantation, and specimens from patients with acute tubular necrosis (ATN) characterized by necrosis of tubular cells without glomerular alterations. LCs purified from the urine of patients with myeloma cast nephropathy (MCN-LCs) for the in vitro experiments and specimens from biopsies and autopsies from patients with myeloma cast nephropathy for the tissue specimens were employed as internal nonglomerulopathic LC controls.

\section{In Vitro CD68 and SMA Colocalization}

HMCs were cultured as previously described and treated with LCs harvested from the urine of patients with biopsy-proven MCN, LCDD or AL-Am. The cells were grown on chambered glass slides and incubated for $96 \mathrm{~h}$ with the LCs in phenol red-free RPMI 1640 culture medium containing 0.5\% FBS. The HMCs were harvested at the end of the incubation period, then double-stained immunohistochemically using Texas Red dye (CD68) and fluorescein (SMA) tagged secondary antibodies, respectively. Primary antibodies to CD68 and SMA were monoclonal antibodies obtained from DAKO Cytomation and diluted as previously described. The cells were examined using fluorescence microscopy and the images recorded.

\section{In Vitro Assay of HMCs Grown on Matrigel}

Matrigel (BD Biosciences) in its gel-like consistency was poured into the wells of four-well separated 
glass slides (LAB-TEK ${ }^{\circledR}$ ) to provide a membrane base for the attachment and growth of HMCs in culture. HMCs were seeded onto the membranes and allowed to attain $90 \%$ confluency while growing at similar conditions as previously described for our in vitro assays (ie media, incubating conditions, LCs and controls). Membranes and cells were then harvested and fixed in $80 \%$ ethyl alcohol or Carson-Millonig's solution depending on future downstream analysis. The alcohol-fixed specimens were embedded in paraffin and sectioned at $4 \mu \mathrm{m}$ and stained with hematoxylin and eosin, while those fixed for EM were further processed for that procedure. The HMCs were incubated with MCN, LCDD or AL-Am LCs for $96 \mathrm{~h}$ and then the specimens were submitted for ultrastructural processing and examination using a Philips CM12 scanning/ transmission electron microscope (NV Philips, The Netherlands) as described in detail in the section titled ultrastructural examination.

\section{Matrigel Invasion Assay for HMCs}

BD BioCoat Invasion Chambers Cat. \# 354481 (six wells with six inserts) were used in this experiment. The package was removed from storage at $-20^{\circ} \mathrm{C}$ and allowed to attain room temperature. Phenol red-free RPMI 1640 culture medium containing 0.5\% FBS and sodium bicarbonate was warmed to $37^{\circ} \mathrm{C}$ and added in $2.0 \mathrm{ml}$ quantities to the interior of the inserts and the bottom of the wells. The plates were allowed to rehydrate for $2 \mathrm{~h}$ in a humidified (99\%) tissue culture incubator, at $37^{\circ} \mathrm{C}$ and $5 \% \quad \mathrm{CO}_{2}$ atmosphere. Following rehydration, the medium was carefully removed from the chamber and well without disturbing the Matrigel matrix on the membrane.

Third passage (P3) HMCs were prepared in the medium previously described to be seeded at a concentration of 250000 cells/well. A volume of $2.5 \mathrm{ml}$ of culture medium was added to the wells of the BD Falcon plate. Sterile forceps were used to replace the inserts into the wells containing the chemoattractant, followed by the addition of $2.0 \mathrm{ml}$ of cell suspension containing 250000 HMCs. MCN-LC, LCDD-LC, and AL-Am-LC were added to separate wells at a concentration of $10 \mu \mathrm{g} / \mathrm{ml}$. Duplicate sets of cells were incubated for 48, 72 and $96 \mathrm{~h}$ in a humidified tissue culture incubator at $37^{\circ} \mathrm{C}$ and $5 \% \mathrm{CO}_{2}$ atmosphere.

Noninvading cells were removed from the upper surface of the membrane by a 'scrubbing' action. A sterile cotton-tipped swab was inserted into the Matrigel insert and moved over the membrane surface while applying firm, gentle pressure. This scrubbing action was repeated using a second swab moistened with RPMI 1640 medium. The inserts were then fixed in $100 \%$ methanol and stored at $-20^{\circ} \mathrm{C}$ until hematoxylin and eosin staining to identify cells and immunostaining for CD68 expres- sion to highlight transformed HMCs with macrophage phenotype, if cells were found.

\section{Dynamic Studies}

Fifth passage (P5) HMCs were used in this study to examine the dynamic interactions between LCs and HMCs. A 24-well plate was modified to enable warm $\left(37^{\circ} \mathrm{C}\right)$ water to flow between the wells maintaining a constant temperature. A constant flow of $5 \% \mathrm{CO}_{2}$ at a $0.1-0.2 \mathrm{~cm}^{3} / \mathrm{s}$ was also maintained. Purified LCs already described in other experiments and albumin acting as control were used to treat the HMCs.

ER (endoplasmic reticulum), a member of the Dapoxyl dye family ${ }^{32,33}$ and LysoSensor dyes, ${ }^{34}$ which freely penetrate into cells and selectively accumulate in different cytoplasmic compartments, were used for the experiments.

ER-Tracker $^{\mathrm{TM}}$ Blue-White DPX probe, a highly selective and photostable stain for endoplasmic reticulum $^{32}$ was diluted to a working concentration of $1 \mu \mathrm{M}$ using RPMI 1640 containing $0.5 \%$ FBS (Molecular Probes). The HMCs were incubated with prewarmed $\left(37^{\circ} \mathrm{C}\right)$ diluted probe for $30 \mathrm{~min}$ after which they were treated with different LCs and the interactions observed using a fluorescent microscope with digital capabilities. Images were captured at various time points with IP Lab scientific imaging software.

LysoSensor $^{\mathrm{TM}}$ Green DND-189 probe (Molecular Probes) a fluorescent acidotropic probe for labeling acidic organelles such as lysosomes, ${ }^{34}$ was diluted to a working concentration of $50-70 \mathrm{nM}$ using RPMI 1640 containing $0.5 \%$ FBS. The HMCs were incubated with prewarmed $\left(37^{\circ} \mathrm{C}\right)$ diluted probe for 30 min after which they were treated with different LCs and the interactions observed using a fluorescent microscope with digital capabilities. Images were captured at various time points with IP Lab scientific imaging software.

Statistical analysis of the Region of Interest (ROI) was determined by one-way ANOVA followed by post hoc comparisons performed with a Bonferroni/ Dunn test $(P<0.05)$ using the SPSS statistical analysis package.

\section{Ultrastructural Examination}

Specimens for ultrastructural examination were fixed in Carson-Millonig's solution (Polysciences Corporation, Warrington, PA, USA) then embedded in epoxy (Polysciences Corporation) and LR White resins (London Resin, Surrey, England). Thick sections prepared from these preparations were stained with Toluidine for light microscopic survey. Following the selection of appropriate areas, thin sections were prepared and stained with aqueous uranyl acetate and lead citrate (Fisher Scientific). The ultrastructural details of the specimens were examined with a Phillips CM12 scanning/transmission electron microscope (N.V. Phillips, The Netherlands). 


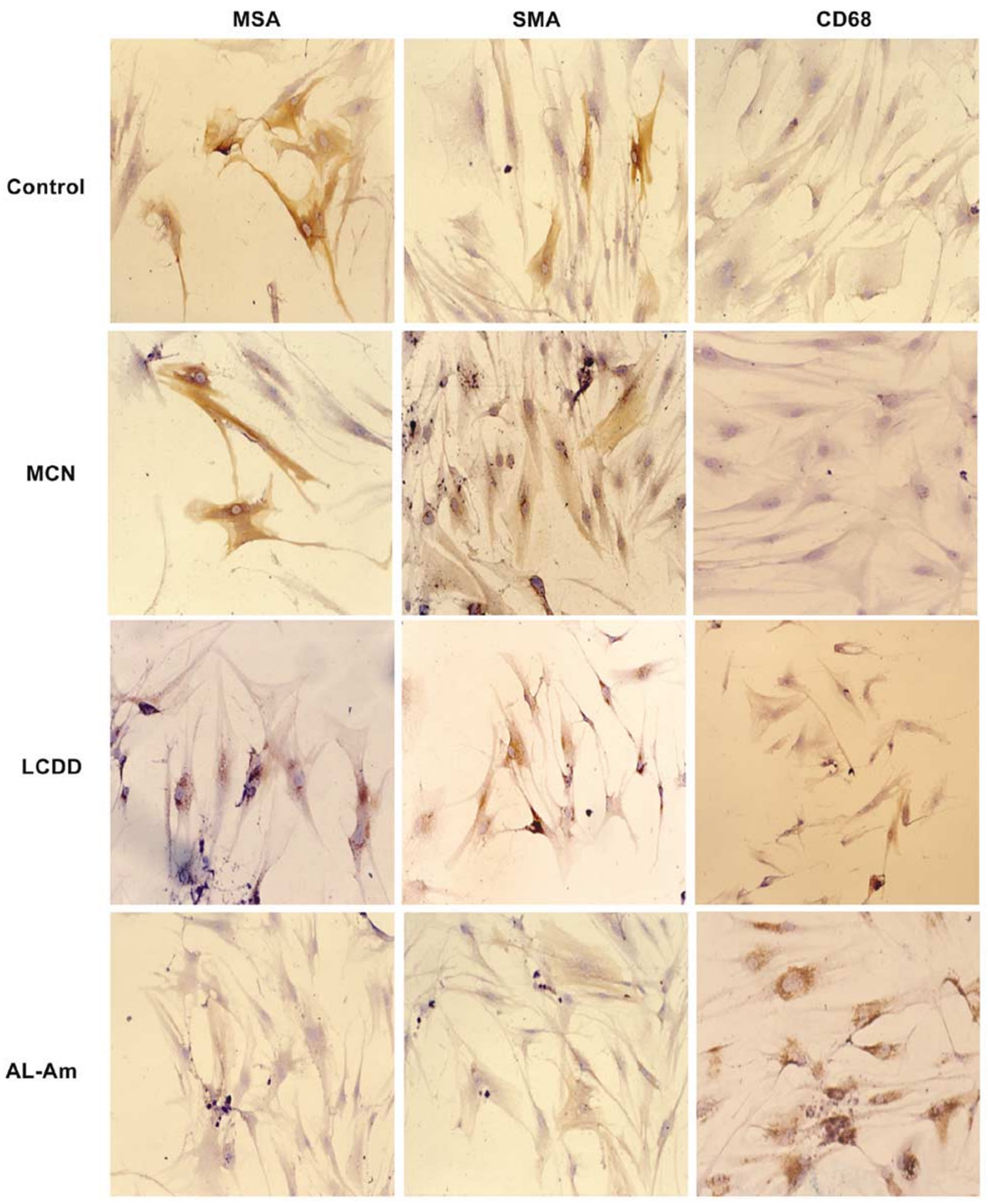

Figure 2 Montage of LC-treated HMCs and controls stained using immunohistochemistry for MSA, SMA and CD68 antigens. Note the more abundant CD68 expression in the AL-Am-LC-treated cells compared to the other categories. Note also the absence of SMA and MSA in the AL-Am-LC-treated cells compared to appreciable expression in the LCDD-LC, MCN-LC-treated and control cells. Immunohistochemistry (DAB as marker) $\times 200$. 


\section{Ultrastructural Labeling}

The specimens, previously embedded in epoxy resins, were sectioned then placed on nickel grids and etched by exposing them to $10 \%$ hydrogen peroxide for $10 \mathrm{~min}$. Those specimens embedded in LR White resin did not require initial etching. Immunogold labeling was performed as previously described by Herrera and Lott. ${ }^{35}$ Specimens on uncoated nickel grids were incubated in 3\% normal goat serum (Vector Laboratories, Inc.) for blocking. This was followed by incubation with polyclonal $\kappa$ and $\lambda$ antibodies (Dako Corporation) diluted 1:1000, for $16 \mathrm{~h}$ at $4^{\circ} \mathrm{C}$. After washing, the grids were incubated with a 1:20 dilution of a $15 \mathrm{~nm}$ goldlabeled antiserum to rabbit immunoglobulin (Janssen Pharmaceutical, Beerse, Belgium) for $1 \mathrm{~h}$. The grids were then poststained with aqueous uranyl acetate and lead citrate. A Phillips CM12 scanning/ transmission electron microscope (N.V. Phillips) was used to examine the specimens. Positive control consisted of a $\kappa$ LCDD case, while negative controls consisted of a minimal change disease case and a focal and segmental glomerulosclerosis case.

\section{Statistical Analysis}

Statistical analysis of the results, where stated was conducted using the Wilcoxon sum-ranked test for nonparametric two-way ANOVA at a confidence interval of $P<0.05$.

\section{Results}

\section{SMA and MSA Immunohistochemical Staining of HMCs In Vitro}

Muscle-specific actin (MSA) and $\alpha$-smooth muscle actin (SMA) expression were observed in the HMCs treated with LCs in the in vitro model. In these experiments, the HMCs showed both MSA and SMA localized to the cytoplasm, though more generally distributed and extending to the cytoplasmic margins (Figure 2). Greater expressions of MSA and SMA were noted in the LCDD-treated HMCs than in cells treated with the other LCs (AL-Am \& MCN) and control. In all cases, the expression of SMA was observed to be much higher than that of MSA. Manual grading of these markers in 50 HMCs confirmed these observations and established statistical significance (Figure 3).

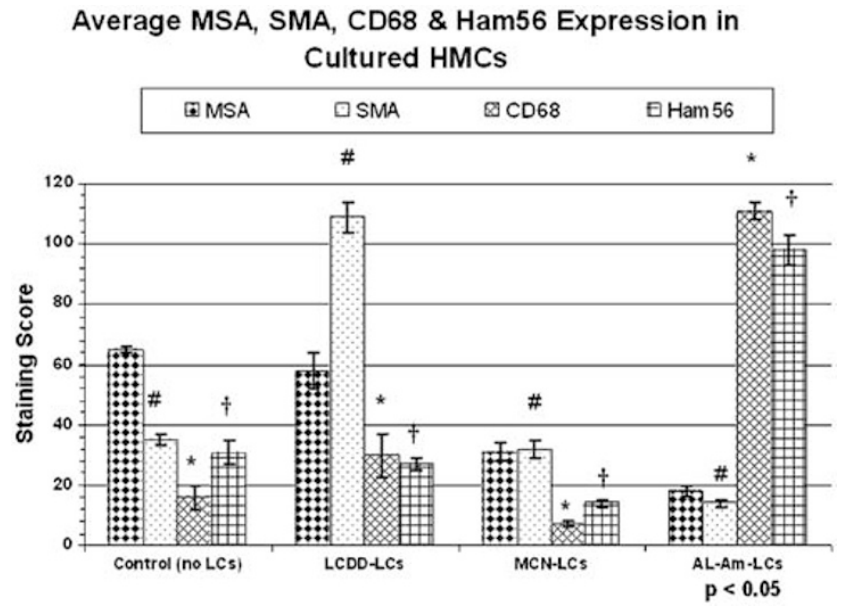

Figure 3 Average MSA, SMA, CD68 and HAM56 expression by the cultured HMCs stained using immunohistochemistry. Statistically significant differences were noted for the SMA $\left({ }^{*}\right)$, CD68 $(\#)$ and HAM56 $(\dagger)$ expression staining intensities of the AL-Am, LCDD and control treated cells.

\section{CD68 Immunohistochemical Staining of HMCs In Vitro}

CD68 and HAM56 expression was monitored in the HMCs cultured with LCs for $96 \mathrm{~h}$. HMCs treated with AL-Am-LC showed greater expression levels than the LCDD-LCs, myeloma cast nephropathy light chains (MCN-LC) and control cells (Figure 2). Staining was cytoplasmic and more intensely localized to the perinuclear regions of the cells with a granular appearance (Figure 2). Manual grading of 50 cells revealed an approximately three- and fourfold (statistically significantly) higher CD68 and HAM56 expression, respectively, in the AL-Am LC-treated cells compared to those treated with LCDD-LCs (Figure 3).

\section{MSA and SMA Expression in Renal Glomeruli}

The CD68 monoclonal antibody used in this study recognizes lysosomal-associated membrane proteins (LAMPs) expressed by lysosomes. CD68 staining in the renal glomeruli was consistent in the specimens expressing the antigen, indicating the population of mesangial cells which have been transformed. CD68 was observed to be localized only in HMCs which were transformed (Figure 4) as well as in blood vessels in the renal specimens. A statistically significant 12-fold higher CD68 staining was noted in the AL-Am cases compared to the LCDD cases (Figure 5).

Figure 4 Montage of glomeruli from different categories of renal tissue stained by immunohistochemistry for MSA, SMA, and CD68 expressions. Glomeruli from all categories except AL-Am show prominent expressions of both MSA and SMA. Note that CD68 expression is abundant in the AL-Am case while absent or present in lesser amounts in all the other categories. The arrow in the AL-Am glomeruli indicates an area of early amyloid deposition surrounded by numerous CD68-positive mesangial cells. Immunohistochemistry (DAB as marker) $\times 400$. 
MSA

NEG

MCN
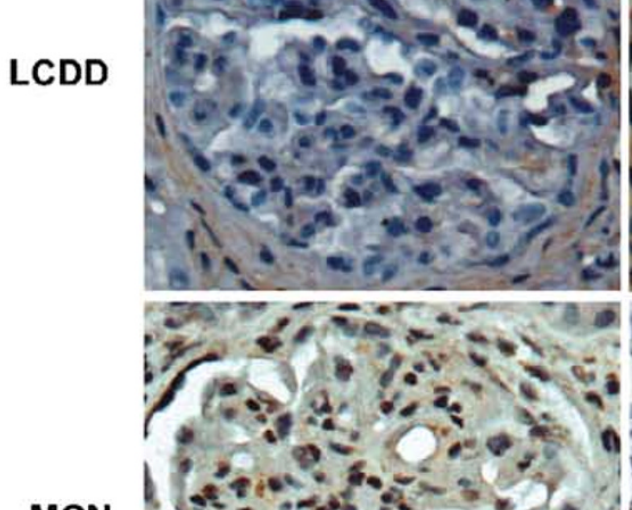

SMA

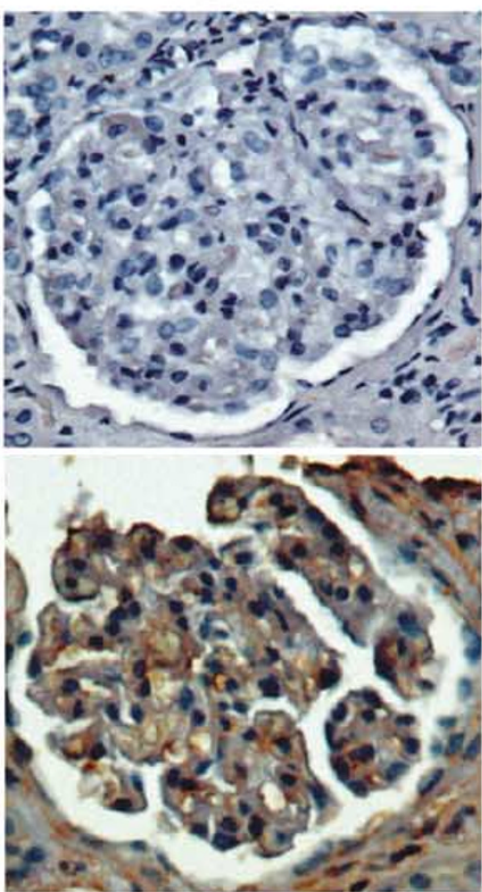

\section{CD68}

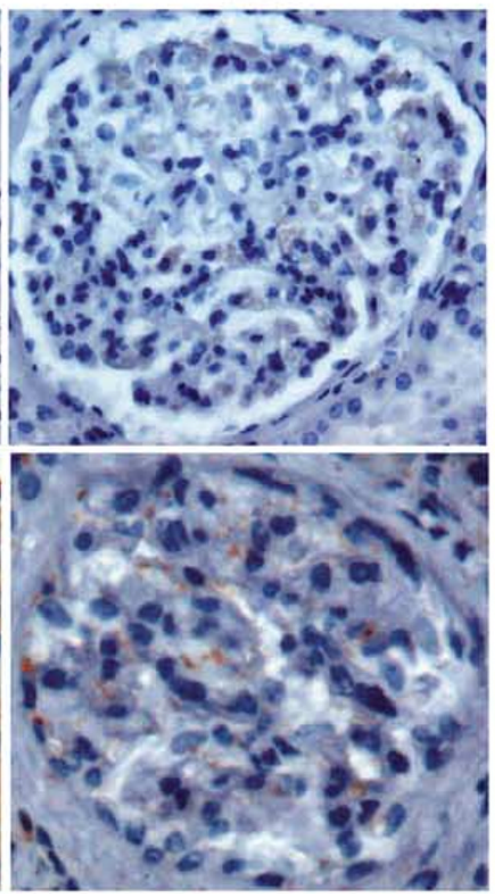

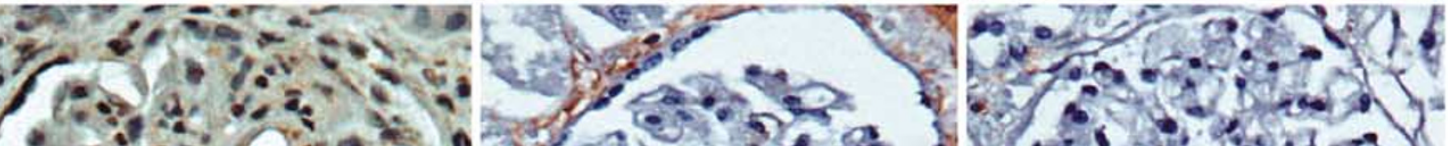

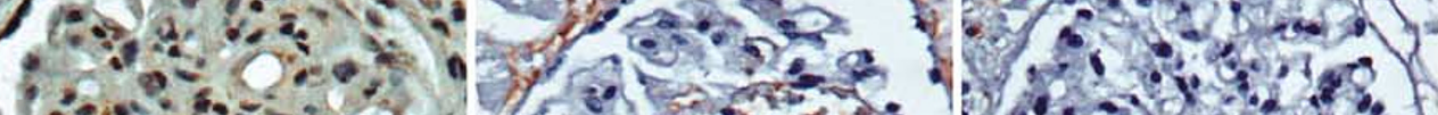

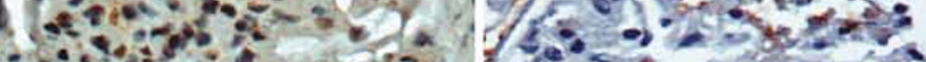

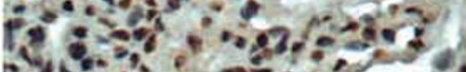

가. L.

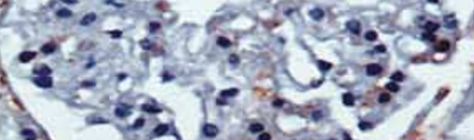

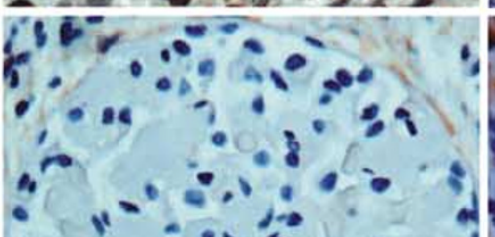

AL-Am
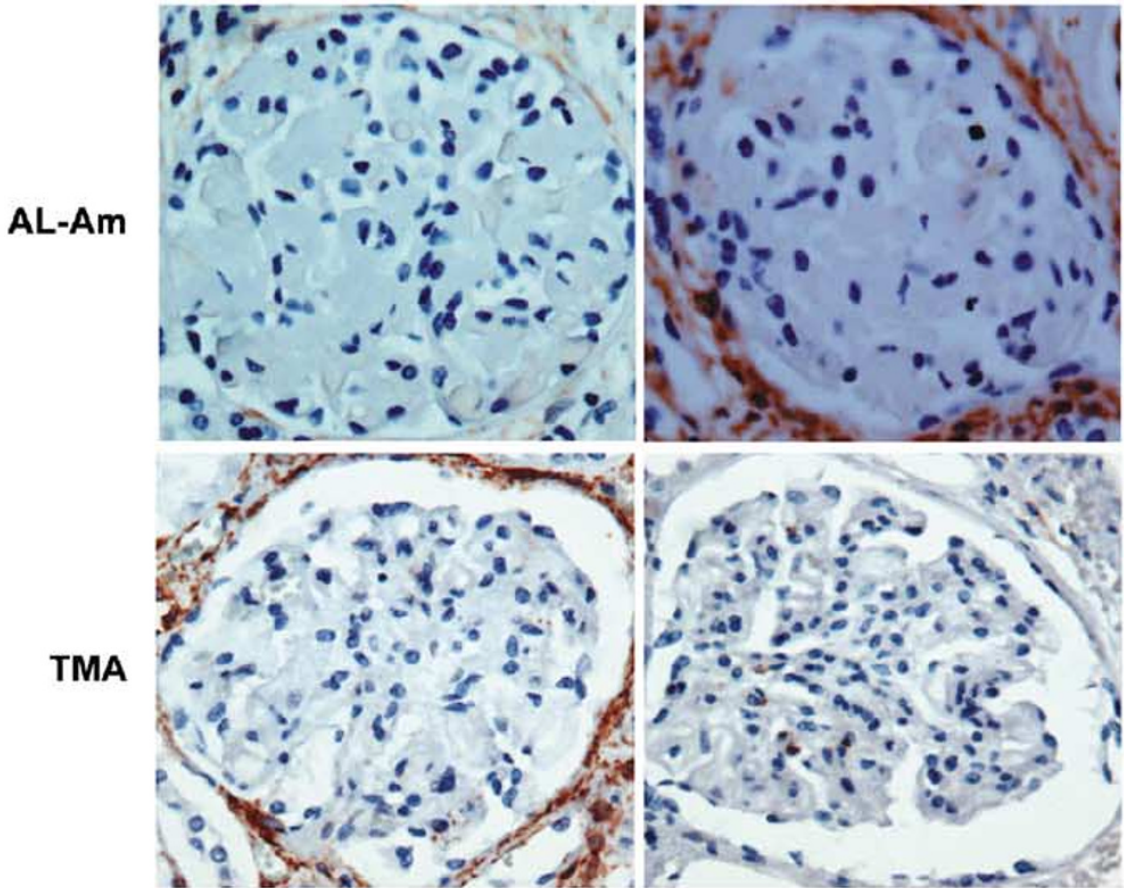

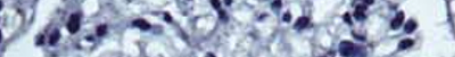
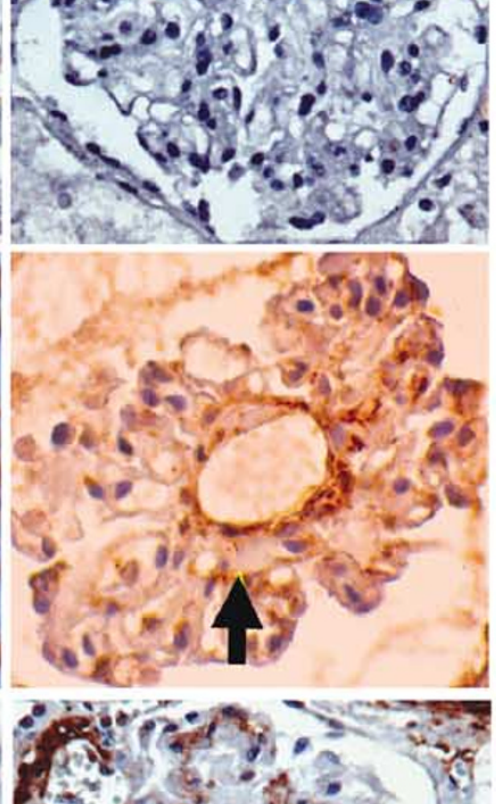

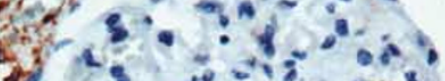

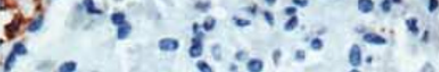

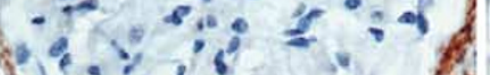

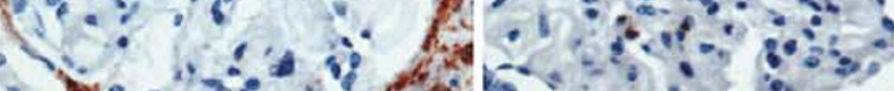

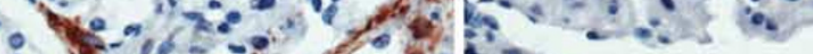

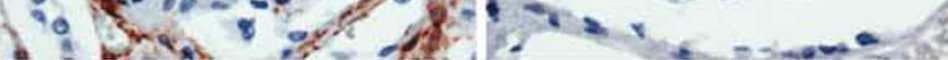

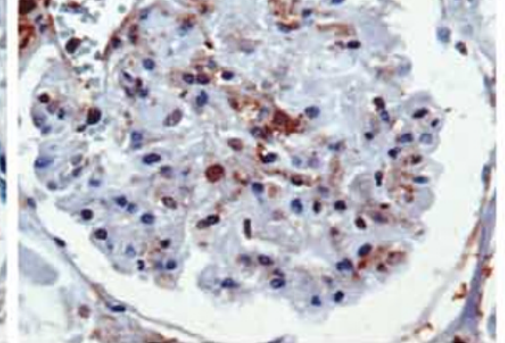


Average MSA, SMA, \& CD68 Expression in Renal Glomeruli

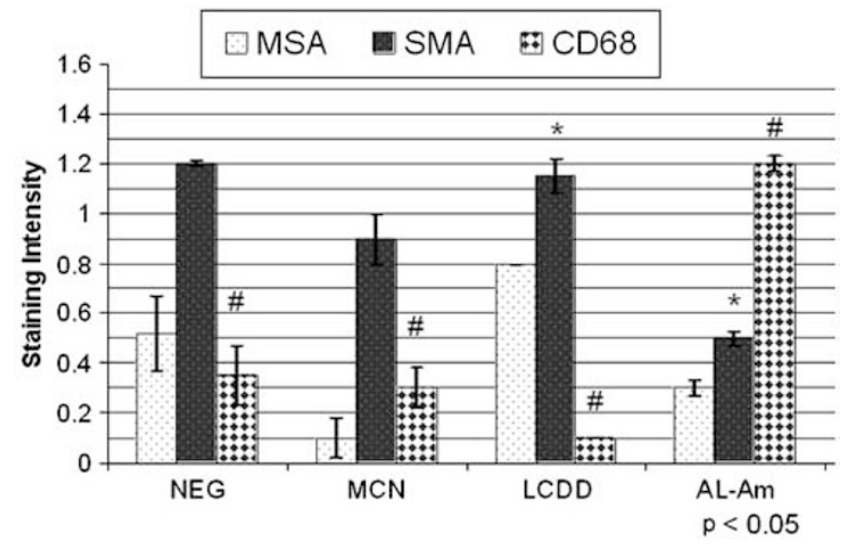

Figure 5 Average MSA, SMA and CD68 expression in the renal glomeruli stained using immunohistochemistry. Statistically significant differences were noted for the SMA $\left(^{*}\right)$ staining intensities of the AL-Am and LCDD cases and for the CD68 (\#) expressions between the AL-Am cases and all other categories.

\section{CD68 Expression in Renal Glomeruli}

Both MSA and SMA were expressed in the glomeruli of cases from all the categories studied, although, the level of SMA expression was higher in all cases compared to MSA (Figures 4 and 5). Glomeruli from the LCDD cases expressed significantly ( $>$ two fold) more MSA and SMA than the AL-Am cases (Figure 5).

\section{In Vitro CD68 and SMA Colocalization}

It was noted that some HMCs which were incubated with AL-Am-LCs expressed both CD68 and SMA. CD68 was identified by the presence of red color (having been localized by the Texas red-labeled secondary antibody to CD68), SMA filaments were identified by the green fluorescein-labeled secondary antibody to the SMA protein. Coexpression of both proteins was determined by the presence of a yellow color in the cytoplasm of the treated HMCs (Figure 6a) indicating the presence of cells with smooth muscle and macrophage characteristics ('hybrid cells').

\section{CD14 Expression in Renal Glomeruli and HMCs In Vitro}

No CD14 expression at all was identified in renal glomeruli or in HMCs incubated with the various LCs for $96 \mathrm{~h}$.

\section{CD34 Expression in HMCs in Culture}

Only rare CD34-positive cells (less than 1\% of all cells) were detected in HMCs incubated with LCDD,
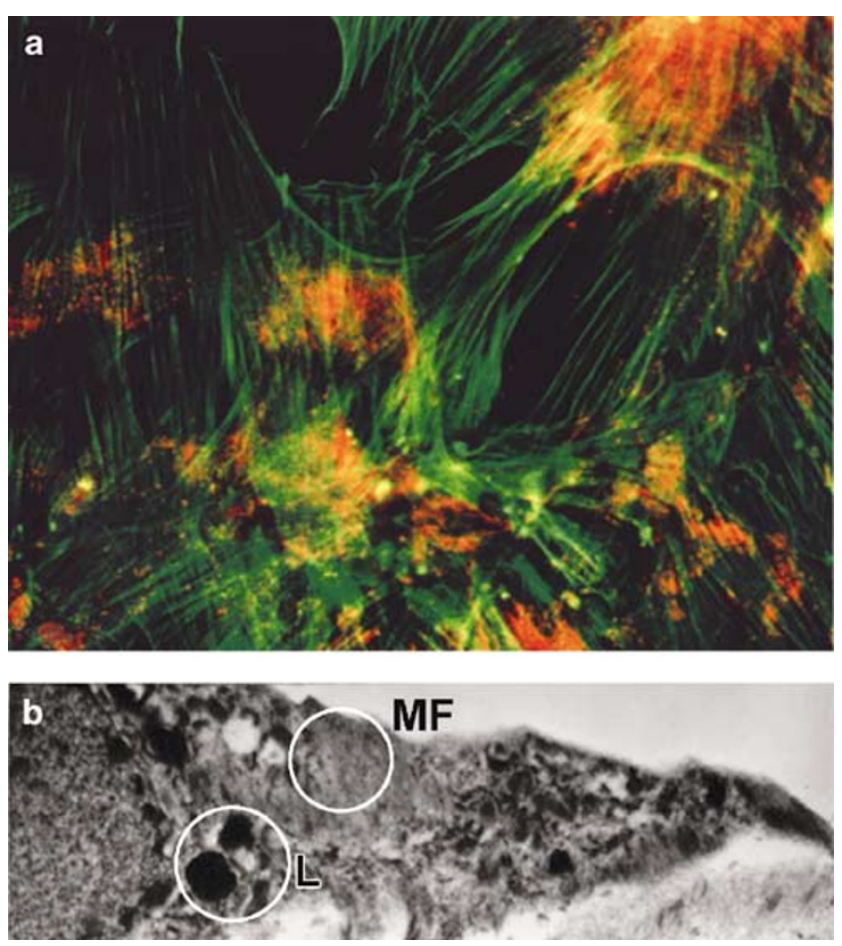

Figure 6 Evidence of the 'hybrid' cell. AL-Am-LCs-treated HMCs double stained for SMA (green) and CD68 (red) are shown in Figure $5 \mathrm{a}$ with areas of antigenic colocalization appearing yellow $(\times 400)$. Ultrastructural analysis of the 'hybrid' HMC shows prominent lysosomes (L) and myofilaments (MF) in (b). TEM (uranyl acetate and lead citrate) $\times 18500$.

AL-Am and MCN-LCs or with albumin or no LCs, indicating the virtual absence of primitive bone marrow cell markers. There were no differences in the number of CD34-positive HMCs in the various experimental conditions.

\section{LCs Detection in Amyloid Deposits in HMCs Growing on Matrigel Incubated with AL-Am-LCs}

Monoclonal lambda LC deposition was demonstrated in association with amyloid (Figure $7 \mathrm{a}$ and b). There was no staining for kappa LC associated with amyloid.

\section{Matrigel Invasion Assay for HMCs}

No HMCs were identified in the inserts in specimens incubated with either LCDD, AL-Am, MCNLCs or in HMCs in culture without addition of LCs.

\section{Ultrastructural Evaluation}

Ultrastructural evaluation of the renal specimens and in vitro HMC cultures treated with AL-Am and LCDD-LCs confirmed the presence of hybrid cells. Figure 6b shows a mesangial cell incubated with an AL-Am-LC exhibiting prominent cytoplasmic lyso- 

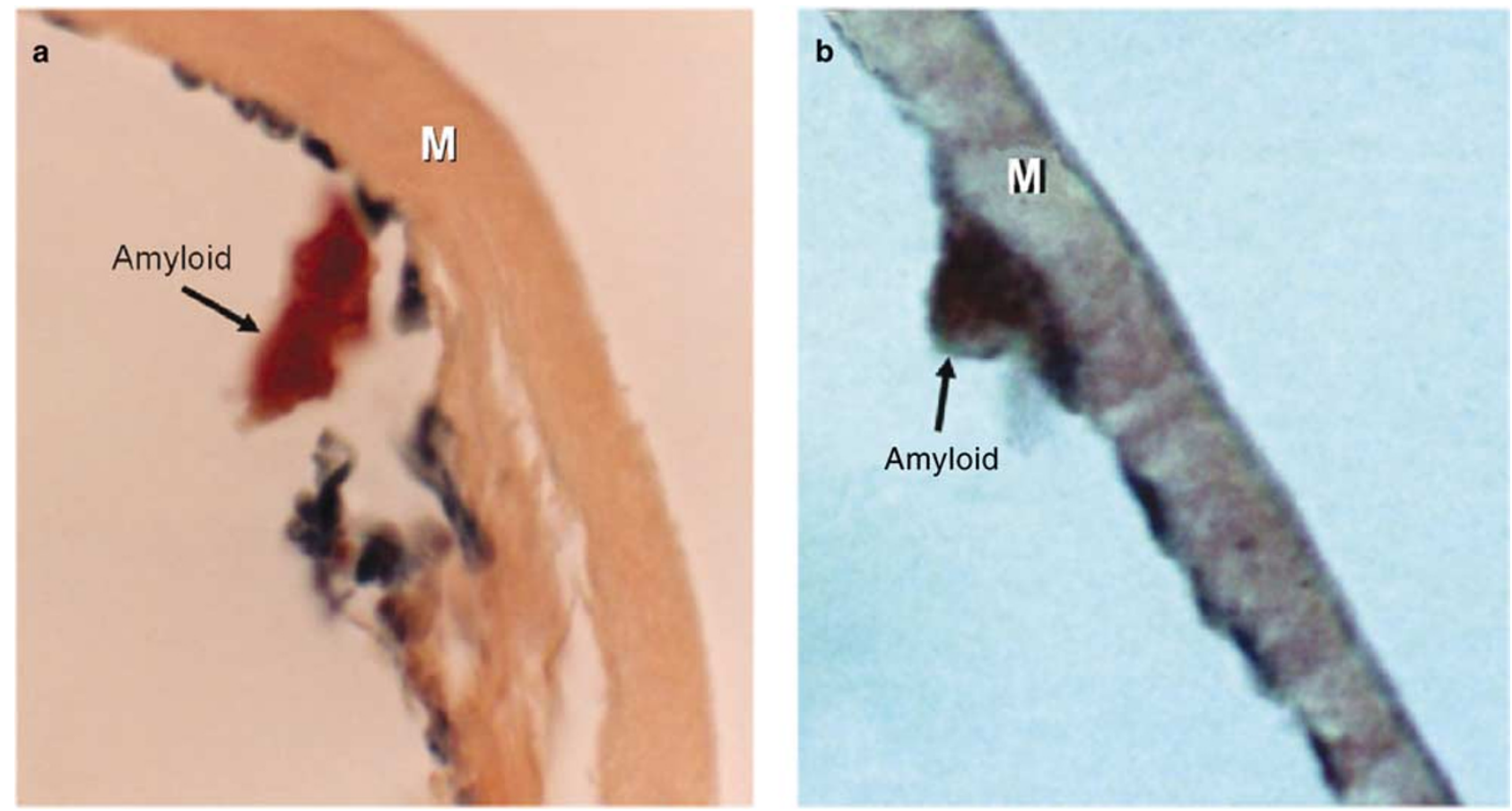

Figure 7 HMCs growing on Matrigel (M) matrix and incubated with AL-Am-LCs for $96 \mathrm{~h}$. Extracellular amyloid is identified in both micrographs (a and b). Congo Red stain and immunohistochemical stain for $\lambda$ LC, respectively, $\times 200$.

somes in a focal cytoplasmic area and myofilaments in another area.

\section{Dynamic Studies}

HMCs incubated with LCDD-LC in the presence of the ER-Tracker showed a significant increase in the presence of RER compared to the cells treated with AL-Am-LC, MCN-LC and albumin (Figure 8). After 150 min of incubation time, significant RER was observed located perinuclearly and radiating out into the cytoplasm of the LCDD-LC-treated HMCs.

Evaluation of the Region of Interest (ROI) where fluorescence accumulated in the cytoplasm of mesangial cells indicating the presence of RER revealed increasing amounts of RER over time (Figure 9).

HMCs incubated with LysoSensor and different LCs were observed. It was noted that the presence of lysosomes increased significantly in the cells treated with AL-Am-LC over incubation time up to $60 \mathrm{~min}$ (Figure 10). At $30 \mathrm{~min}$ the lysosomal density was almost at a maximum; therefore, there is not much difference between Figures 10c and d.

\section{Light Microscopy and Ultrastructural Labeling}

Figures 11a and b show the presence of amyloid in the glomeruli from one of the patients with ALamyloidosis from whom LCs were purified from the urine for the experiments conducted as part of this study. The amyloid deposits were seen throughout the mesangium in Figure 11a by hematoxylin and eosin staining and confirmed by its 'salmon-pink' appearance when stained with Congo Red dye (Figure 11b) and polarized. Ultrastructurally, amyloid fibrils were $7-10 \mathrm{~nm}$ in diameter, nonbranching and haphazardly disposed (Figure 11c) and derived from $\lambda$ LCs (Figure 11d). The microscopic appearance of glomeruli from an LCDD patient from whom urine was purified for the experiments is shown in Figure 12a with distinctive mesangial nodules noted in the hematoxylin-and eosin-stained sections. Ultrastructurally, these nodules contain punctate $\kappa$ LCs deposits as shown in Figure 12b and c, admixed with increased extracellular matrix material.

\section{Light Microscopy and Ultrastructural Labeling of Cultured HMCs}

HMCs grown on Matrigel and treated with AL-AmLCs provided evidence that amyloid was produced by these cells (Figures $7 \mathrm{a}$ and $\mathrm{b}$ ) and the existence of 'hybrid' mesangial cells (Figures 6a and b). Ultrastructural analysis of these HMCs showed three distinct cell types. The 'normal' mesangial cell with its smooth muscle characteristics is shown in Figure 13a, while a cell is seen containing both lysosomes and myofilaments-'hybrid' (Figure 13b) and finally, another is shown containing numerous lysosomes adjacent to an area with amyloid deposition (Figure 13c). A human mesangial cell in culture at a higher magnification confirms the presence of the 

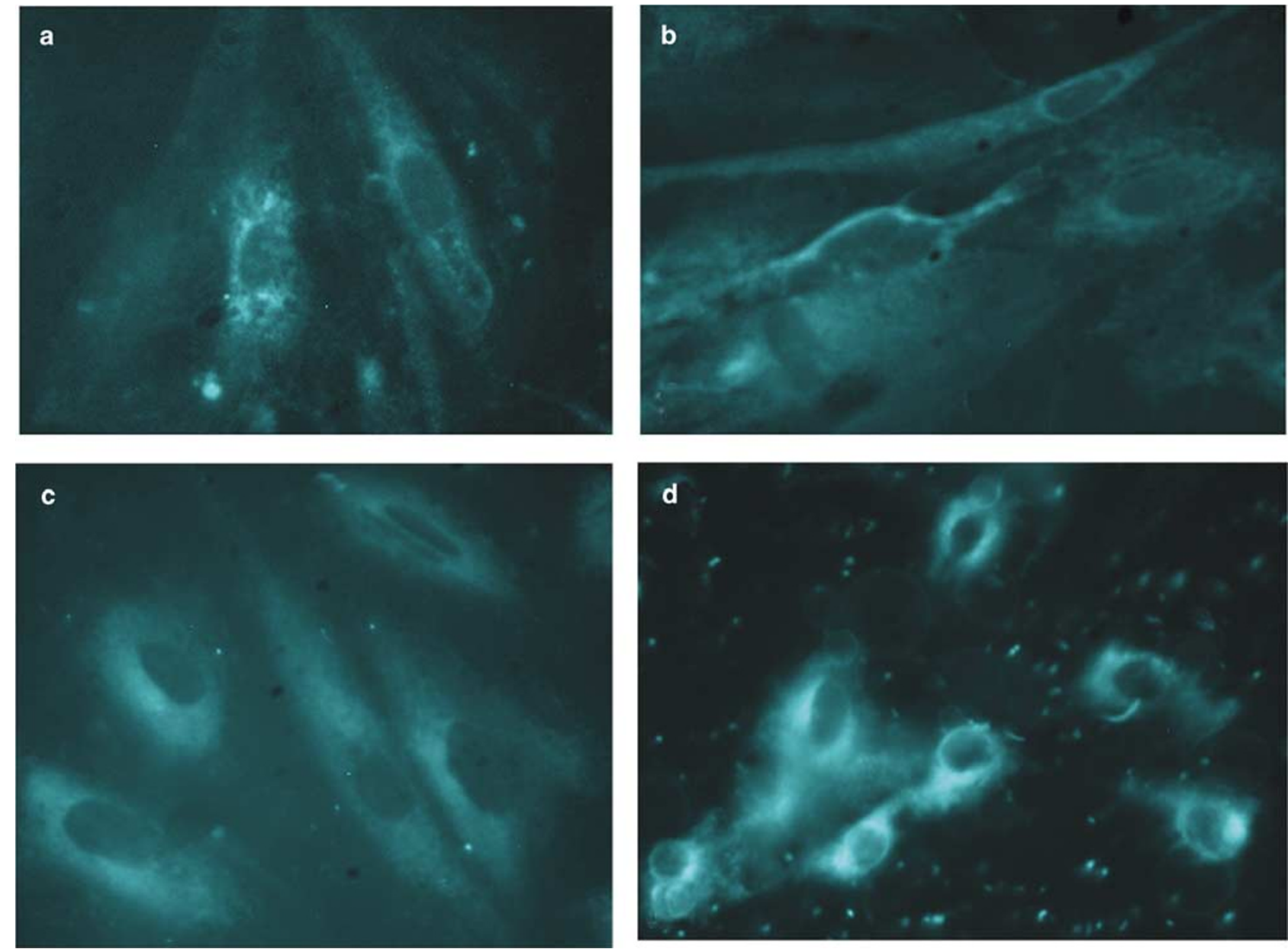

Figure 8 HMCs treated with various LCs and probed with ER Tracker. Note the significantly greater quantities of RER present in the cells treated with LCDD-LC compared the AL-Am and MCN-LCs and albumin-treated cells, as demonstrated by fluorescence intensity in the cytoplasm. Panel (a), albumin treatment; panel (b), MCN-LC; panel (c), AL-Am-LC; panel (d), LCDD-LC-treated cells. Fluorescent microscopy $\times 400$ (panels a-c) and $\times 200$ (panel $\mathbf{d}$ ).

\section{ER expansion in HMCs after incubation with LCDD-LC}

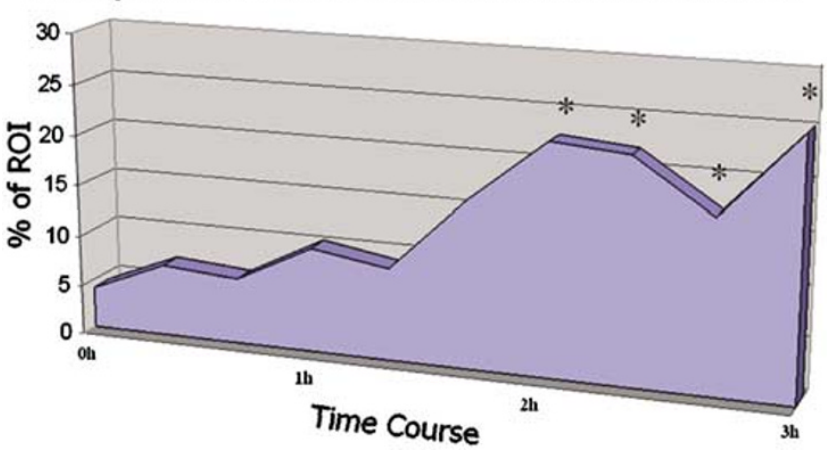

Figure 9 ER expansion in HMCs after incubation with LCDD-LC. Statistical analysis of the Region of Interest focused on the fluorescent labeled region as shown clearly highlights ER enhancement in HMCs incubated with LCDD-LCs. * Denotes statistically significant when compared with baseline $(0 \mathrm{~h})$.

typical fibrils surrounded by lysosomes (Figures 14a and b). Ultrastructural labeling for LCs revealed the presence of $\lambda$ LCs associated with the amyloid deposits (Figure 14b) while CD68 expression in these cells by immunohistochemistry was confirmed in (Figure 14d).

\section{Discussion}

The phenomenon of human mesangial cell phenotypic transformations associated with injury has only been occasionally addressed ${ }^{6,18}$ even in light of similar cellular changes occurring in various renal cell types being documented by a number of authors. ${ }^{36-48}$ Our rationale is based on the belief that different LCs can induce remarkably distinct pathophysiologic changes in the kidney. Said LCs have been classified as either tubulopathic (MCN), or glomerulopathic (AL-Am and LCDD) clearly based on the location in which their pathologic effects are evident. Although both glomeruli and tubules can be affected by the same abnormal LC, mostly one compartment is targeted. Figure 15 serves to illustrate the sequence of events and the outcomes of these mesangial cell-LCs interactions. Notably, LCDD-LC interaction with HMCs results in 

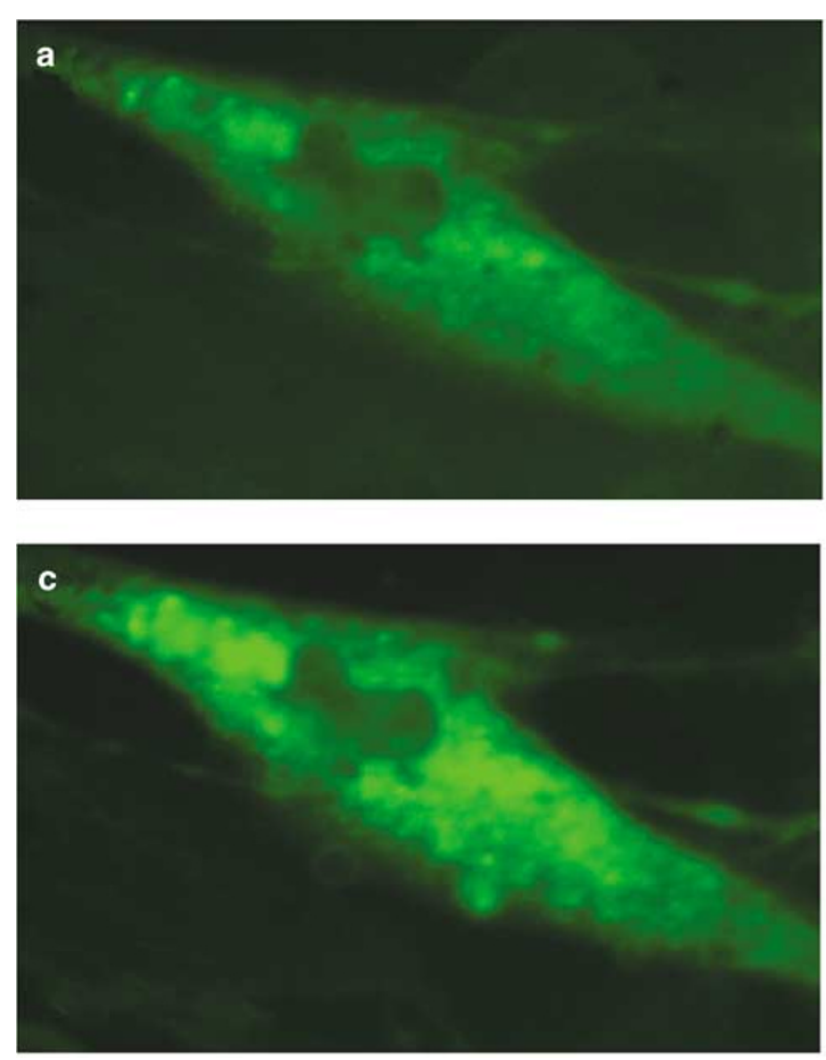
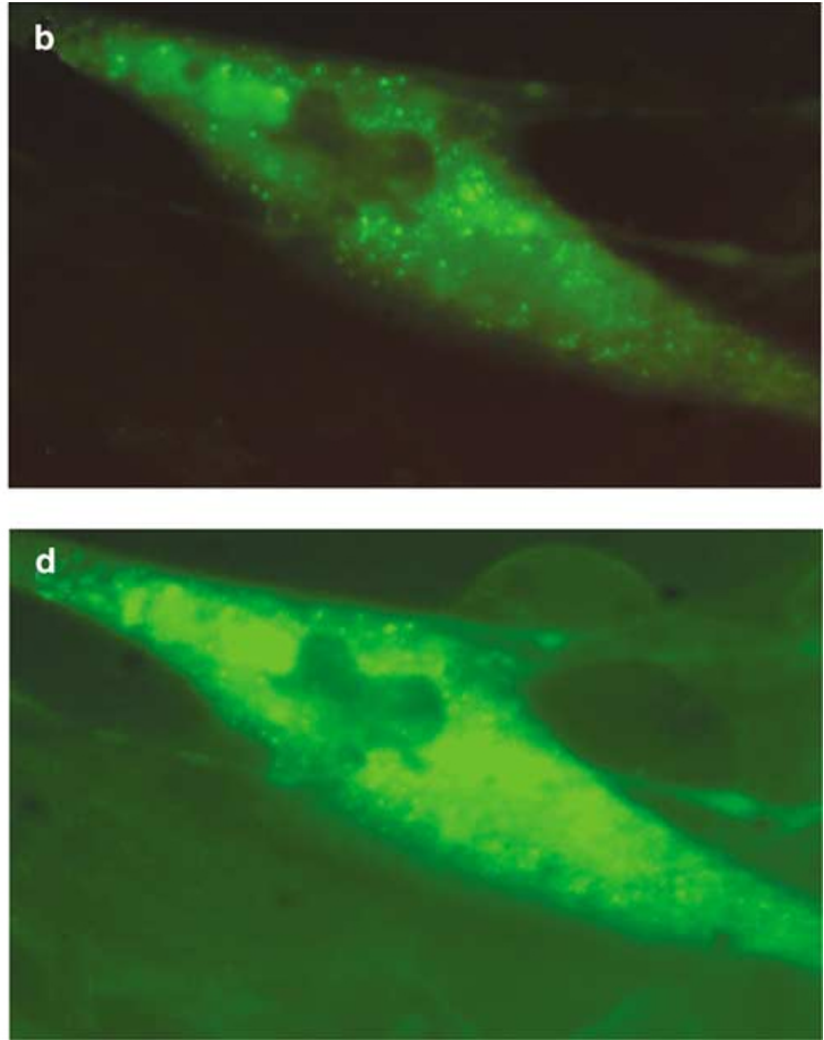

Figure 10 HMCs treated with AL-Am-LCs and probed with LysoSensor. Note the striking increase in LysoSensor fluorescence indicative of an increase in lysosomes over incubation time. Panel (a), 0 min time point; panel (b), 5 min time point; panel (c), 30 min time point; panel (d), 60 min time point. Fluorescent microscopy $\times 400$.

excess production and accumulation of extracellular matrix linked to increased amounts of RER coupled with decreased matrix metalloproteinase (MMP) expression. ${ }^{43}$ Also, mesangial expansion is noted in this disease leading to the formation of nodules composed of extracellular matrix material admixed with LC deposits. However, mesangial cells affected by AL-Am-LCs present a dramatically different picture. Here, MMP expression is significantly increased $^{18,43}$ and abundant lysosomes are present in MCs along with the deposition of amyloid replacing the degraded extracellular matrix.

The entry of LCs into the mesangial cell is believed to be regulated by receptors on the cell's surface. Data obtained in our laboratory indicate the presence of a single cell surface receptor and the different glomerulopathic LCs compete for binding sites on this receptor. ${ }^{44}$ LCDD-LCs are catabolized in the early endosomes, while the AL-Am-LCs have been shown to be transported to the mature lysosomes for processing (Figure 16). Here, these amyloidogenic LCs undergo processing eventually, leading to the formation of amyloid fibrils. The amyloid is then extruded from the cell into the extracellular compartment where it accumulates, resulting in the classical picture of AL-amyloidosis.

Herein, we report our findings of some effects of glomerulopathic LCs on HMCs (Figure 15). Our results in the in vitro studies agree with those of other researchers, that is, injured glomerular cells transform phenotypically. ${ }^{36-40}$ In AL-Am-LCs-induced changes, there is an intermediary step in the HMCs transformation from a smooth muscle phenotype to the macrophage phenotype. Evidence in support of this can be seen in Figure 6, where hybrid cells were observed expressing both CD68 and MSA in a colocalized manner. However, as the transformation process progresses and more lysosomes are acquired by the MCs, they lose their actin filaments and consequently their ability to function as contractile cells. This renders them incapable of maintaining mesangial turgidity and homeostasis as their new role is now primarily concerned with endocytosis of the LCs and the increased production of MMPs. A similar phenotypic change has been described in vascular smooth muscle cells in Alzheimer amyloid $\beta$ protein deposition. ${ }^{45}$ Furthermore, the lysosomes acquired by the mesangial cells are morphologically most compatible with primary lysosomes, not autophagosomes (heterophagosomes) which may be acquired by cells as a nonspecific response to injury. These lysosomes actively engage in LC processing, as has been clearly shown in previous studies. ${ }^{44}$

Although these HMCs express CD68 and exhibit prominent lysosomes, they are not true tissue 

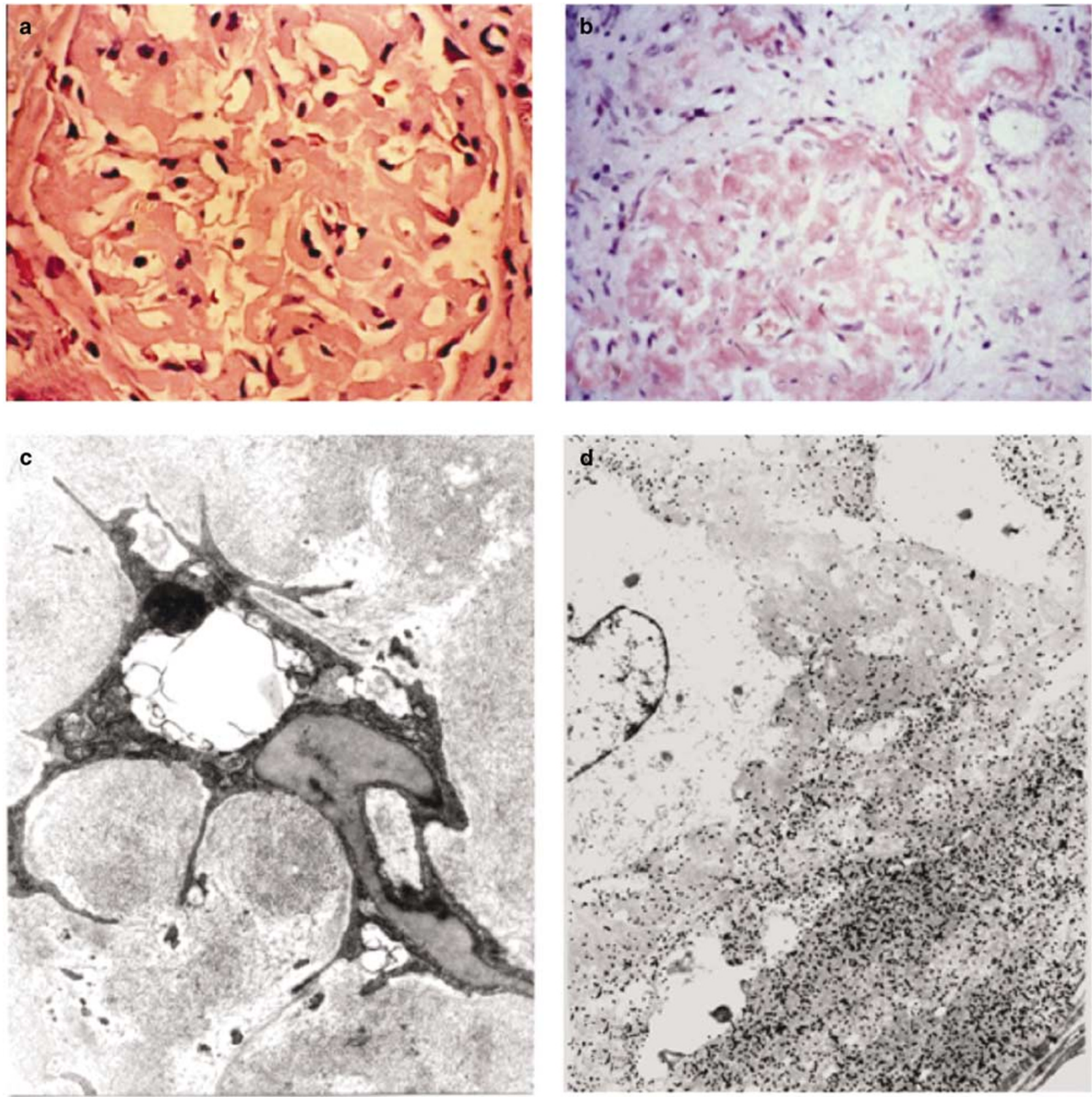

Figure 11 Light microscopy and ultrastructural findings from a renal biopsy specimen of an AL-Am case. Amyloid deposits are noted in the H\&E stained $(\times 400)$ glomeruli $(\mathbf{a})$, and confirmed with Congo Red staining $(\mathbf{b})$ exhibiting a salmon pink appearance. A macrophage type of mesangial cell is noted associated with numerous fibrils with characteristics of amyloid $(\times 22500)(\mathbf{c})$ and $\lambda$ LCs are highlighted by immunogold labeling (d) using $20 \mathrm{~nm}$ gold particles $(\times 35000)$.

macrophages. Invasion experiments conducted showed no evidence of these cells traversing the membrane of the Boyden Chambers even after $96 \mathrm{~h}$ of incubation. These transformed MCs do not become motile scavengers within the mesangium, but rather remain in situ engaged in the internalization and processing of amyloidogenic LCs. If these cells are unable to recover from the injury, death (likely through apoptosis) occurs, contributing to loss of glomerular function. ${ }^{46}$
It is well established that not all types of injury to the glomerulus results in its demise. ${ }^{47,48}$ Spontaneous recovery from glomerular diseases involving the mesangial vasculature has been reported. ${ }^{49,50}$ It has been reported that the recovery of the mesangium is related to its ability to regenerate normal vasculature with proliferating endothelial cell expressing angiogenic factors. ${ }^{49}$ This glomerular rebirth has been attributed to repopulation by cells from the bone marrow. ${ }^{12,49,50}$ These provocative studies suggest that perhaps all glomerular 

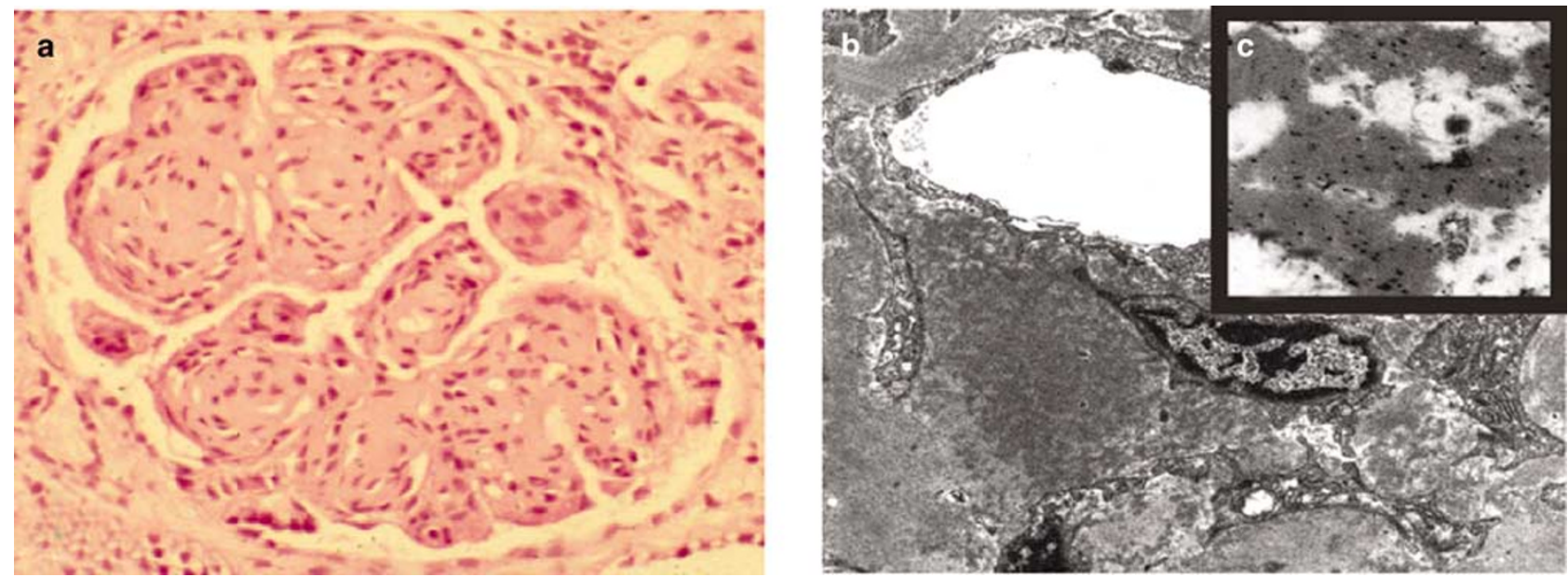

Figure 12 Light microscopy and ultrastructural findings from a renal biopsy specimen of an LCDD case showing mesangial nodules with increased extracellular matrix H\&E stain, $\times 400$ (a). Punctate deposits of $\kappa$ LCs (b) are demonstrated using immunogold labeling to be $\kappa$ LC related; (c) TEM (uranyl acetate and lead citrate): $\times 22500$ and 35000 , respectively.

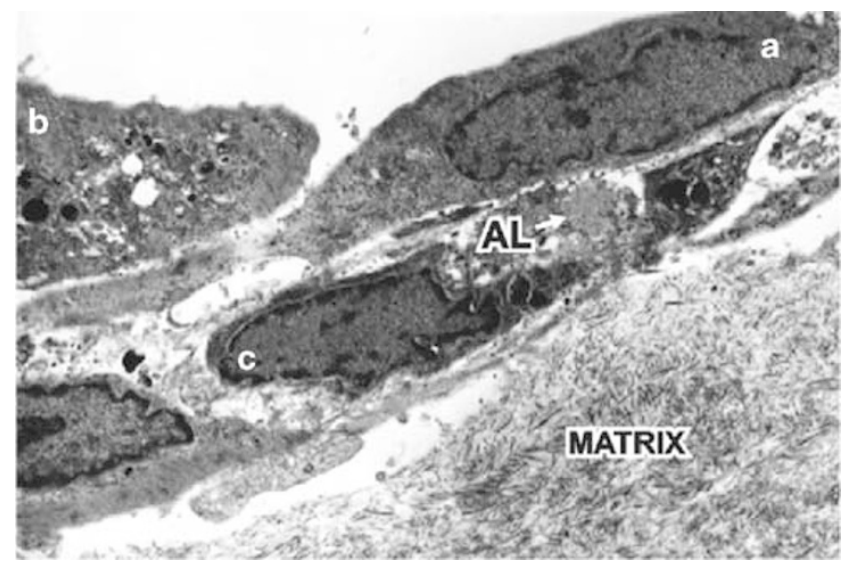

Figure 13 Ultrastructural representations of HMCs in culture treated with AL-Am-LCs. A normal HMC is shown (a), a partially transformed (hybrid) cell (b), and fully transformed cell (c) containing amyloid (AL). These cells were grown on a Matrigel matrix. TEM (uranyl acetate and lead citrate) × 16500 .

cell types can be repopulated from pleuripotent bone marrow precursor cells. The evidence suggests that mesangial cells are among those that can be replenished by bone marrow cells, possibly from mesenchymal stem cells. ${ }^{12,51}$ Recently, mesangial cells have been reported to 'trans' or dedifferentiate due to injury from the mature 'mesangiocyte' to the 'mesangioblast' (an embryonic myofibroblast), ${ }^{41}$ which exhibit the characteristics of myofibroblasts similar to those seen associated with LCDD. This evidence, therefore, argues that the mesangium is capable of its own cellular regeneration following injury. The data presented in this manuscript supports that the phenotypical transformation that occurs in mature mesangial cells is a process independent of a bone marrow-related healing process. These two processes, however, mesangial cell transformation and bone marrow-derived cell repopulation as a 'healing' mechanism are not mutually exclusive. Additional work is needed to clearly define how much bone marrow cells can contribute to mesangial regeneration.

CD68 and HAM56 expression in the cultured HMCs treated with AL-Am-LCs was greater than its expression in the LCDD-LCs-treated counterpart. The control cells and those treated with MCN-LCs showed little CD68 and HAM56 expression, as was expected. Random grading of 50 mesangial cells from the various categories revealed a statistically significant difference in CD68 and HAM56 expression by the AL-Am when compared with LCDD-LCs treated and control cells.

Examination of the glomeruli from patients with AL-amyloidosis expressed 12-fold more CD68 than those with LCDD. This was a statistically significant finding $(P<0.05)$. The results obtained from the negative cases revealed a 3.4-fold decreased expression of CD68 compared to the AL-Am cases which was also statistically significant $(P<0.05)$. CD68, not a cell surface marker, recognizes the lysosomalassociated membrane proteins (LAMPs) present on mature (late) lysosomes. ${ }^{23}$ In addition, CD14 was investigated as a marker for monocytes. CD14 was not expressed by the mesangial cells in any of the glomeruli examined or in HMCs incubated with the various LCs. The absence of CD-34-positive cells in vitro and in vivo mitigates against the presence of pluripotential bone marrow stem cells participating in this process.

The experiments conducted to investigate the expression of MSA and SMA provided evidence of a unique relationship between the HMCs expressing these antigens and CD68. It was noted from the in vitro studies, HMCs treated with AL-Am-LCs had lower expression levels of both MSA and SMA 

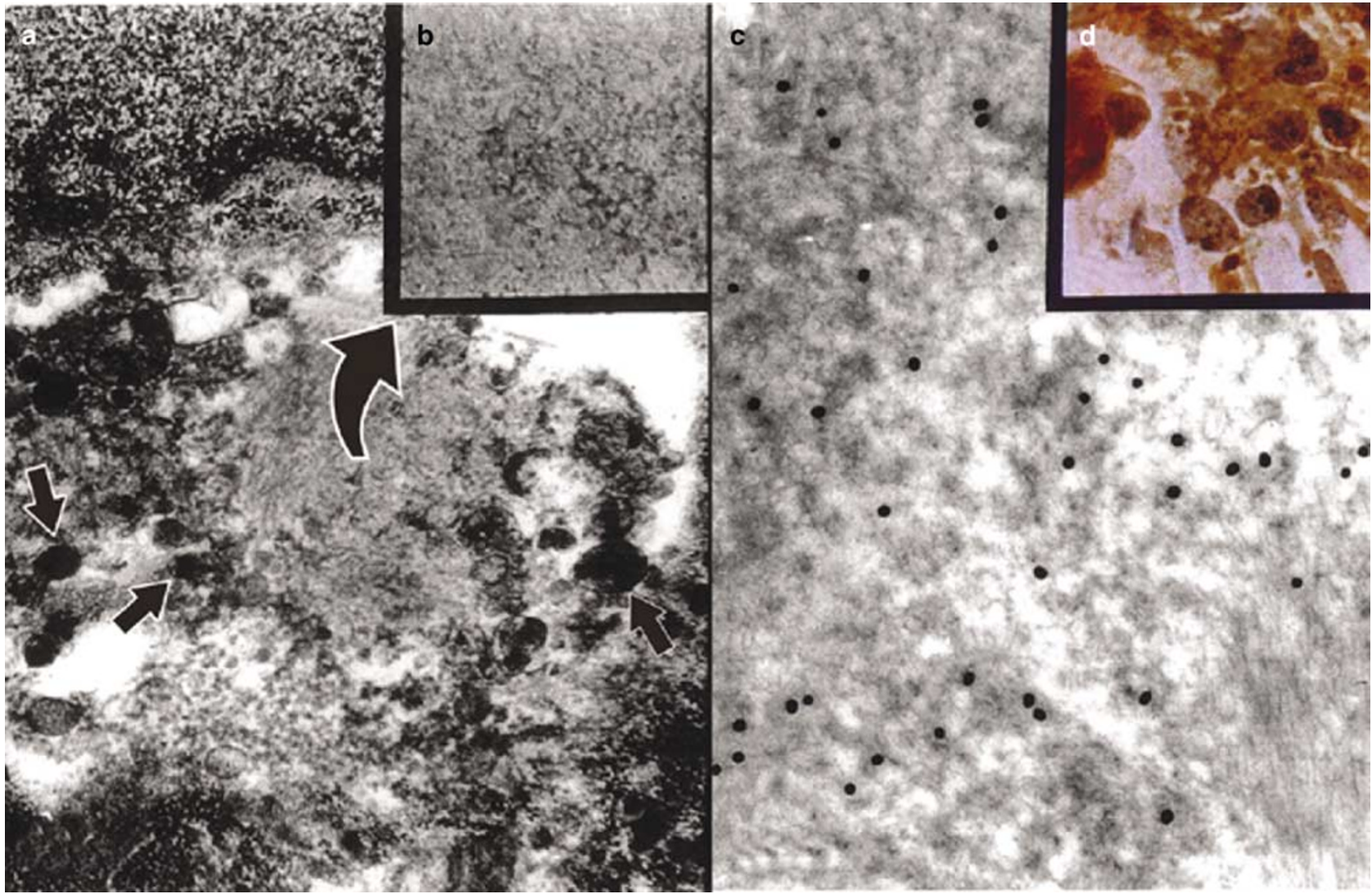

Figure 14 Higher magnifications (TEM using uranyl acetate and lead citrate $\times 22500$ ) of the amyloid deposits in the transformed HMC showing numerous mature lysosomes surrounding the deposits (a). Amyloid is noted as typical fibrils in (b). Ultrastructural (TEM $\times 35000)$ immunogold labeling identifies $\lambda$ LCs $(20 \mathrm{~nm}$ gold particles) among the fibrils (c) and CD68 immunohistochemistry (DAB $\times 400)$ of these cells show strong positivity $(\mathbf{d})$.

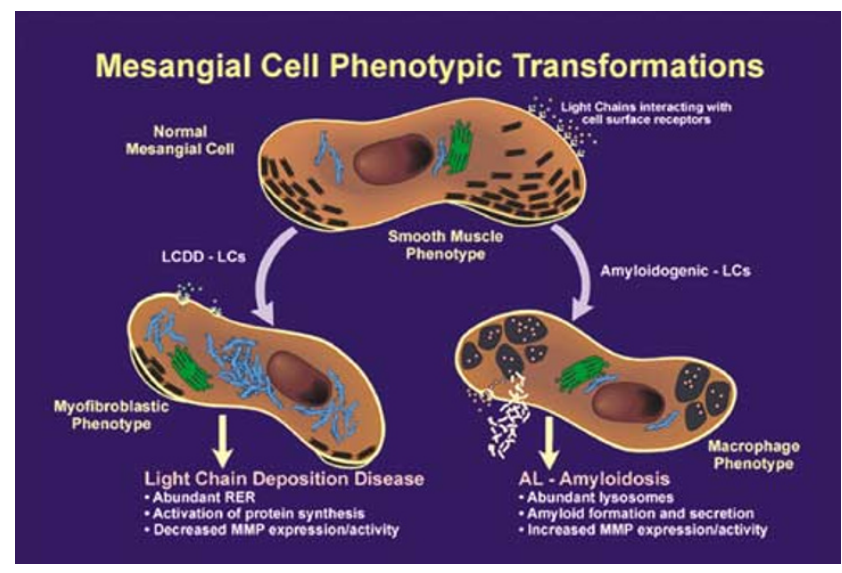

Figure 15 Transformation pathways by HMCs affected by either AL-Am-LCs or LCDD-LCs. Note amyloidogenic LCs induce a macrophage phenotypic transformation, while a myofibroblastic phenotype is induced following LCDD-LC interactions.

compared to the LCDD-LC-treated cells and the controls. These findings corroborate the observations of others that injury to HMCs usually causes an increase in SMA expression. ${ }^{1,6,14}$ These findings were recapitulated in the renal tissues studied.

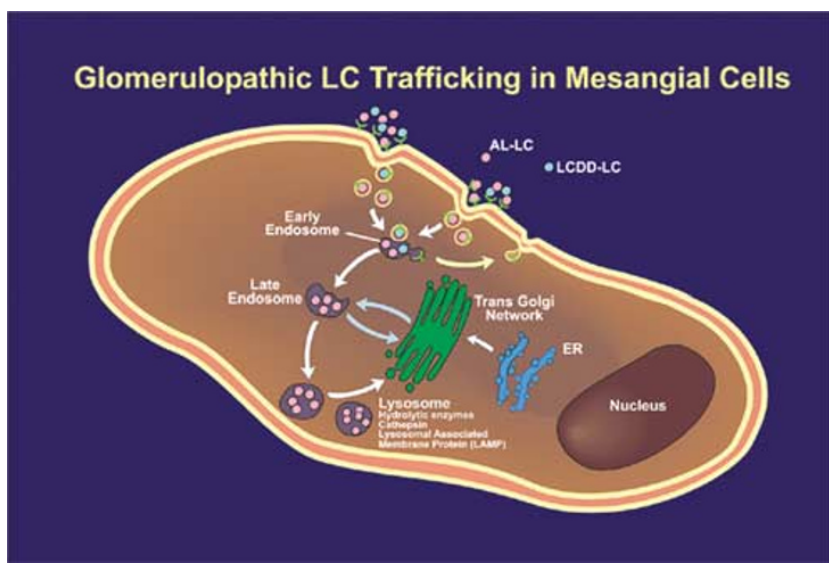

Figure 16 Trafficking of glomerulopathic LCs in the human mesangial cell is shown. AL-Am-LCs which are avidly internalized by the HMCs, are shown to travel through the early endosomes and delivered to the mature lysosomes where they are processed. Conversely, LCDD-LCs, if internalized, are catabolized in the early endosomes.

However, as shown in this study, not all types of injury results in increased SMA expression (ie ALamyloidosis). 
The data obtained from the dynamic studies clearly show that HMCs treated with LCDD-LC acquire significantly greater quantities of RER compared to normal HMCs, consistent with their transformation to myofibroblasts. This is in keeping with our hypothesis where these cells produce increased quantities of ECM proteins, especially tenascin. Conversely, using a LysoSensor probe, it was noted that the HMCs incubated with AL-Am-LC showed abundant lysosomes throughout their cytoplasms. This finding is further proof that these cells acquire morphologic features indicative of transformation to a macrophage phenotype.

The biologic process in which mesangial cells engage upon exposure to either AL-Am or LCDDLCs is, in our opinion, best referred to as transformation whereby a mesenchymal cell type is transformed to another (smooth muscle cell type to myofibroblast in LCDD and to macrophage in ALAm). The term transdifferentiation (across cell lines) is best used for cellular transformation of one lineage to another (ie epithelial to mesenchymal) and does not seem to be appropriate for the phenotypic mesangial cell alterations reported in this study. Unfortunately, these two terms are used interchangeably in the literature creating confusion.

We have shown that two distinct phenotypic transformations occur in HMCs depending on the type of glomerulopathic LCs these cells are exposed to. HMCs exposed to LCDD-LCs transform to a myofibroblastic phenotype expressing increased amounts of actin proteins and decreased CD68. These myofibroblastic cells engage in active production of extracellular matrix components, such as fibrillary collagens and tenascin, which normal mesangial cells do not normally. The antigenic expression patterns are the direct inverse in HMCs exposed AL-Am-LCs where CD68 is more highly expressed than the actin proteins; typical of a macrophage phenotype. Also, the transformation processes in these HMCs progress through an intermediary phenotype, giving rise to hybrid cells, where lysosomes are present admixed with myofilaments in their cytoplasms. The dynamic studies described in this manuscript provide additional proof of the rewired internal circuitry occurring in the mesangial cells as they are affected by different LCs.

\section{Acknowledgements}

We wish to thank Dr L Joseph and Dr B Barlogie from the University of Arkansas for Medical Sciences for their help in the acquisition of the autopsy renal specimens. Also, thanks to Dr YM Tagouri for his contribution in the early experimental work which enhanced the quality of this manuscript.

\section{References}

1 Johnson RJ, Floege J, Yoshimura A, et al. The activated mesangial cell: a glomerular 'myofibroblast'? J Am Soc Nephrol 1992;2:S190-S197.

2 Davies M. The mesangial cell: a tissue culture view. Kidney Int 1994;45:320-327.

3 Schlondorff D. The glomerular mesangial cell: an expanding role for a specialized pericyte. FASEB J 1987;1:272-281.

4 Holthofer H, Sainio K, Miettinen A. The glomerular mesangium: studies of its developmental origin and markers in vivo and in vitro. APMIS 1995;103:354-366.

5 Schlondorff D. Roles of the mesangium in glomerular function. Kidney Int 1996;49:1583-1585.

6 Johnson RJ. The glomerular response to injury: progression or resolution. Kidney Int 1994;45: 1769-1782.

7 Gabbiani G. Evolution and clinical implications of the myofibroblast concept. Cardiovas Res 1998;38: $545-548$.

8 Floege J, Radeke HR, Johnson RJ. Glomerular cells in vitro versus the glomerulus in vivo. Kidney Int 1994;45:360-368.

9 Elger M, Drenckhahn D, Nobiling R, et al. Cultured rat mesangial cells contain smooth muscle $\alpha$-actin not found in vivo. Am J Pathol 1993;142:497-509.

10 Hegele RG, Behar M, Katz A, et al. Immunocytochemical characterization of cells in rat glomerular culture. Clin Invest Med 1989;12:181-186.

11 Stamenkovic I, Skalli O, Gabbiani G. Distribution of intermediate filament proteins in normal and diseased human glomeruli. Am J Pathol 1986;125:465-475.

12 Imasawa T, Utsunomiya Y, Kawamura T, et al. The potential of bone marrow-derived cells to differentiate to glomerular mesangial cells. J Am Soc Nephrol 2001;12:1401-1409.

13 Skalli O, Ropraz P, Trzeciak A, et al. A monoclonal antibody against $\alpha$-smooth muscle actin: a new probe for smooth muscle differentiation. J Cell Biol 1986; 103:2787-2796.

14 Gonlusen G, Ergin M, Paydas S, et al. The expression of cytoskeletal proteins (alpha-SMA, vimentin, desmin) in kidney tissue: a comparison of fetal, normal kidneys, and glomerulonephritis. Int Urol Nephrol 2001;33:299-305.

15 Bellotti V, Mangione P, Merlini G. Review: immunoglobulin light chain amyloidosis-the archetype of structural and pathogenic variability. J Struct Biol 2000;130:280-289.

16 Solomon A, Frangione B, Franklin EC. Bence Jones proteins and light chain of immunoglobulins. Preferential association of the $\lambda$ VI subgroup of human light chains with amyloidosis AL. J Clin Invest 1982;70: 453-460.

17 Comenzo RL, Zhang Y, Martinez C, et al. The tropism of organ involvement in primary systemic amyloidosis: contributions of Ig $\mathrm{V}_{\mathrm{L}}$ germ line gene use and clonal plasma cell burden. Blood 2001;98:714-720.

18 Herrera GA, Russell WJ, Isaac J, et al. Glomerulopathic light chain-mesangial cell interactions modulate in vitro extracellular matrix remodeling and reproduce mesangiopathic findings documented in vivo. Ultrastruct Pathol 1999;23:107-126.

19 von Gise H, Christ H, Bohle A. Early glomerular lesions in amyloidosis. Electron microscopic findings. Virchows Arch A Pathol Anat Histol 1981;390:259-272. 
20 Herrera GA. Renal manifestations of plasma cell dyscrasias: an appraisal from the patient's bedside to the research laboratory. Ann Diag Pathol 2000;4: 174-200.

21 Hrncic R, Wall J, Wolfenbarger DA, et al. Antibodymediated resolution of light chain-associated amyloid deposits. Am J Pathol 2000;157:1239-1246.

22 Herrera GA, Russell WJ, Cardelli J. Phenotypic transformation of mesangial cells precedes and is required for AL-amyloidogenesis. In: Bely M, Apathy A (ed). Amyloid and Amyloidosis. The Proceedings of the IXth International Symposium on Amyloidosis. Budapest, Hungary, 2001, pp 267-272.

23 Pulford KA, Rigney EM, Micklem KJ, et al. KP1: a new monoclonal antibody that detects a monocyte/macrophage associated antigen in routinely processed tissue sections. J Clin Pathol 1989;42:414-421.

24 Shirahama T, Cohen AS. An analysis of the close relationship of lysosomes to early deposits of amyloid. Am J Pathol 1973;73:97-114.

25 Shirahama T, Cohen AS. Intralysosomal formation of amyloid fibrils. Am J Pathol 1975;81:101-116.

26 Darby I, Skalli O, Gabbiani G. $\alpha$-Smooth muscle actin is transiently expressed by myofibroblasts during experimental wound healing. Lab Invest 1990;63: 21-29.

27 Gabbiani G, Ryan GB, Majno G. Presence of modified fibroblasts in granulation tissue and their possible role in wound contraction. Experientia 1971;27:549-550.

28 Ronco PM, Alyanakian M-A, Mougenot B, et al. Light chain deposition disease: a model of glomerulosclerosis defined at the molecular level. J Am Soc Nephrol 2001;12:1558-1565.

29 Striker LJ, Doi T, Elliot S, et al. The contribution of glomerular mesangial cells to progressive glomerulosclerosis. Sem Nephrol 1989;9:318-328.

30 Harper PA, Robinson JM, Hoover RL, et al. Improved methods for culturing rat glomerular cells. Kidney Int 1984;26:875-880.

31 Shi S, Coote RJ, Taylor CR. Antigen retrieval immunohistochemistry: past, present, and future. J Histochem Cytochem 1997;45:327-343.

32 Diwu Z, Lu Y, Zhang C, et al. Fluorescent molecular probes II. The synthesis, spectral properties and use of fluorescent solvatochromic Dapoxyl dyes. Photochem Photobiol 1997;66:424-431.

33 Cole L, Davies D, Hyde GJ, et al. ER-Tracker dye and BODIPY-brefeldin A differentiate the endoplasmic reticulum and golgi bodies from the tubular-vacuole system in living hyphae of Pisolithus tinctorius. J Microsc 2000;197(Part 3):239-249.

34 Diwu Z, Zhang Y, Haugland RP. Novel site-selective fluorescent probes for lysosomes and acidic organelle staining and long-term tracking. Cytometry Supple 1994;7:77 (abstract 426B).

35 Herrera GA, Lott RL. Colloidal gold labeling for diagnostic pathology. Colloidal Gold: Principles, Methods and Applications. Academic Press: MA, Hayat, New York, 1990, pp 321-342.
36 Bariéty J, Bruneval P, Hill GS, et al. A 9 transdifferentiation of epithelial glomerular cells. J Am Soc Nephrol 2003;14:S42-S47.

37 Baud L. Renal epithelial cells: differentiation and plasticity. J Am Soc Nephrol 2003;14:S1-S2.

38 Bariéty J, Nochy D, Mandet C, et al. Podocytes undergo phenotypic changes and express macrophagic-associated markers in idiopathic collapsing glomerulopathy. Kidney Int 1998;53:918-925.

39 Bariéty J, Bruneval P, Hill G, et al. Posttransplantation relapse of FSGS is characterized by glomerular epithelial cell transdifferentiation. J Am Soc Nephrol 2001;12:261-274.

40 Bariéty J, Bruneval P, Mandet C, et al. Glomerular and tubular epithelial cell transdifferentiation into myofibroblast in Wegener's crescentic GN. J Am Soc Nephrol 2001;12:3779A.

41 El Nahas AM. Plasticity of kidney cells: role in kidney remodeling and scarring. Kidney Int 2003;64: 1553-1563.

$42 \mathrm{Liu}$ Y. Epithelial to mesenchymal transition in renal fibrogenesis: pathologic significance, molecular mechanism, and therapeutic intervention. J Am Soc Nephrol 2004;15:1-12.

43 Keeling J, Dempsey S, Russell WJ, et al. Matrix metalloproteinases in light chain (LC)-mediated glomerular injury. J Am Soc Nephrol 2002;13:537A.

44 Teng J, Russell WJ, Gu X, et al. Different types of glomerulopathic light chains interact with mesangial cells using a common receptor but exhibit different intracellular trafficking patterns. Lab Invest 2004;84: $440-451$.

45 Urmoneit B, Prikulis I, Wihl G, et al. Cerebrovascular smooth muscle cells internalize Alzheimer amyloid beta protein via a lipoprotein pathway: implications for cerebral amyloid angiopathy. Lab Invest 1997;77: 157-166.

46 Tagouri YM, Sanders PW, Shu L, et al. Glomerulopathic monoclonal light chains potentiate mesangial cell apoptosis. in vitro (abstract). Lab Invest 1995;92, 161A; Misc: Mod Pathol 8: 161A.

47 Abouna GM, Adnani MS, Kremer GD, et al. Reversal of diabetic nephropathy in human cadaveric kidneys after transplantation in non-diabetic recipients. Lancet 1983;2:1274-1276.

48 Clark G, White RH, Glasgow EF, et al. Poststreptococcal glomerulonephritis in children: clinico-pathologic correlations and long-term prognosis. Pediatr Nephrol 1988;2:381-388.

49 Iruela-Arispe L, Gordon K, Hugo C, et al. Participation of glomerular endothelial cells in the capillary repair of glomerulonephritis. Am J Pathol 1995;147:1715-1727.

50 Rookmaaker MB, Smits AM, Tolboom H, et al. Bonemarrow-derived cells contribute to glomerular endothelial repair in experimental glomerulonephritis. Am J Pathol 2003;163:553-562.

51 Poulsom R, Alison MR, Cook T, et al. Bone marrow stem cells contribute to healing of the kidney. J Am Soc Nephrol 2003;14:S48-S54. 